\title{
MOVPE Self-Assembly and Physical Properties of Free-Standing III-V Nanowires
}

\author{
Paola Prete ${ }^{1}$ and Nicola Lovergine ${ }^{2}$ \\ ${ }^{1} I M M$-CNR, Lecce Research Unit, Lecce, \\ ${ }^{2}$ Dept. of Innovation Engineering, University of Salento, Lecce, \\ Italy
}

\section{Introduction}

Quasi 1-dimensional (quasi-1D) semiconductor nano-crystals (so-called nanowires) represent the forefront of today's solid state physics and technology. These systems, having two of their dimensions comparable to the wavelengths of the electronic or phononic wavefunctions, are expected to show a variety of quantum confinement effects, such as density of state singularities, molecular-like states extending over large distances, high luminescence efficiencies and low lasing threshold: these properties have led to consider quasi-1D nanostructures as the fundamental building blocks for the realization of novel types of photonic and electronic nano-devices. The high surface-to-volume ratio of these nanostructures allows also to exploit the role of surface states (and their ambient-driven changes) in determining the nanostructure carrier transport and optical excitation/recombination properties.

Despite the abovementioned attractive physical and technological assets, until very recently, not too many studies were performed on quasi-1D semiconductor systems, whilst twodimensional (2D) structures - quantum wells - have been under study already for more than three decades and quasi zero-dimensional (0D) objects - quantum dots, QDs - have been in the focus of researchers for nearly two decades. The main reason for such discrepancy resides in the difficulty of fabricating these nanostructures. In the recent past, quasi-1D nanostructures of III-V compound semiconductors have been generally grown on three-dimensional patterned (V-grooved) substrates (Kapon, 1994), or on high-index (such as $\{$ n11\}-oriented) substrate planes (Nötzel \& Ploog, 2000). In such cases the major nanowire dimension was running in the substrate plane, with the consequence, however, that interactions with the substrate may dominate over 1D effects. These difficulties have lead to consider free-standing quasi-1D nano-crystals having negligible interaction with the substrate.

Free-standing nanowires based on III-V compound semiconductors are nowadays in the focus of intense research activities throughout the world; this in reason of the prominent role of these compounds in the optoelectronic arena. Demonstration of resonant tunnelling diodes (Bjork et al. 2002; Wensorra et al., 2005), single electron transistors (Thelander et al., 2003; Thelander et al., 2005), and photodetectors (Pettersson et al., 2006) based on quasi-1D nanostructures of III-V compounds have been reported. Also intense single photon sources have been fabricated by embedding InGaP quantum dots in free-standing $\mathrm{GaP}$ nanowires 
(Borgström et al., 2005). Nanowires of InP (Goto et al., 2009) and GaAs (Colombo et al., 2009) were also recently shown to have photovoltaic (PV) properties, with photon energy conversion efficiencies exciding a few percent; theoretical considerations suggest that these structures may be ideal building blocks for the realization of high efficiency PV cells.

Relatively short free-standing semiconductor nanowires (nanorods) can be synthesized in colloidal form by reactions of suitable chemical precursors in coordinating solvents (Shieh, 2005), and afterwards collected on a suitable solid support (glass, silica) for study and/or device fabrication. However, crystallographically-oriented (i.e., epitaxial) quasi-1D nanostructures and their arrays can be grown (monolithically) on single-crystal substrates, provided their major dimension is running out of the substrate plane. The fabrication of free-standing quasi-1D semiconductor nanostructures of III-V compounds is currently investigated by exploiting different combinations of nano-technological methods and advanced epitaxial growth techniques, among the latter, molecular beam epitaxy (MBE), metalorganic vapour phase epitaxy (MOVPE) and other vapour phase growth methods; a major advantage of epitaxial technologies is that they promise precise and reproducible control over the nanowire size, shape, material composition and/or intentional doping along either the nanowire length or the lateral directions. Moreover, vapour epitaxy methods (in special MOVPE) represent the industry standard process for the mass production of most III-V based semiconductor devices; their exploitation in achieving the controlled self-assembly of III-V nanowires would then allow an easy integration of future nanowire-based devices with the current planar-device III-V technology.

In the following, we will briefly review the different approaches being currently explored for the fabrication of free-standing quasi-1D nanostructures of III-V compound semiconductors utilizing the MOVPE technology: major limitations and advantages will be discussed. In particular, we will focus on the self-assembly of semiconductor nanowires by the so-called metal-catalyst assisted - or VLS - mechanism. The latter is currently considered a most promising technology for the realization of high quality quasi-1D nanostructures. Examples of this approach will be given based on results obtained in the author's laboratory using low pressure MOVPE to growth nanowire structures of III-As compounds.

\section{2. "Top-down" versus "bottom-up" technologies for III-V nanowire fabrication}

The fabrication of nanostructured materials is generally achieved by two well-known alternative nano-technological approaches: (i) subtractive (so called "top-down") methods, where excess material is physically or chemically removed from an otherwise bulk-like or epitaxially micro-structured material; or (ii) additive (so called "bottom-up") methods, relying on the ability to self-assemble the nanostructure atom-by-atom (or molecule-bymolecule) up to the final dimensions.

A typical "top-down" approach to the fabrication of epitaxial quasi-1D nanostructures would utilize nano-lithographic techniques, such as electron beam lithography (EBL) and proximal probe patterning, in combination with dry-etching methods to remove excess material from planar epitaxial structures (Wensorra et al., 2005). However, top-down methods do not warrant a sufficiently low dimensionality, the spatial resolution limit of nano-lithographic techniques being typically above the size $(20 \mathrm{~nm})$ below which quantumconfinement effects appear in these nanostructures. Moreover, the resulting nano-crystals 
may suffer from process damages and surface roughening that could seriously deteriorate their electronic and/or optical properties.

"Bottom-up" methods achieving quasi-1D nanocrystals through self-assembly growth methods allow a superior crystalline perfection and size down to a few tens of nm; moreover, these methods allow the fabrication of quasi-1D nanostructures with compositional modulations along the nanowire axis (quasi-1D heterostructures) or in the radial direction (so-called core/shell nanostructures), which cannot be easily achieved by "top-down" approaches or chemical solution methods. In the field of MOVPE, two alternative bottom-up technologies for fabrication of III-V nanowires are being considered: (i) selective area epitaxy (SAE) (Motohisa et al., 2004), and (ii) metal-catalyst assisted selfassembly (Hiruma et al., 1995), through the so-called Vapour-Liquid-Solid (VLS) mechanism.

In the case of SAE, a (111)-oriented (III-V or Si) substrate is first covered with a thin (usually $20 \mathrm{~nm}) \mathrm{SiO}_{2}$ mask and circular openings with diameters of 50-200 $\mathrm{nm}$ are then fabricated in the mask by standard EBL and plasma etching processes. At relatively high temperatures $\left(650 \div 750^{\circ} \mathrm{C}\right)$ III-V nanowires can then be grown by MOVPE within the mask openings with size comparable to the opening diameters and lengths up to several microns; the nanowires grow preferentially along the substrate (111) direction, i.e. with their major direction normal to the substrate plane (Motohisa et al., 2004). A clear advantage of this method is its ability to control the exact nanowire position on the substrate. Controlling the nanostructure positions and density across the substrate surface could pave the way to the realization of large and dense periodic arrays of almost identical quasi-1D nanostructures, the latter having potential applications in the field of 2-dimensional photonic crystal cavities and waveguides. Highly ordered arrays of GaAs (Noborisaka et al., 2005a) and InP/InAs/InP core-multishell (Mohan et al., 2006) nanowires, have been recently demonstrated. However, the method appears restricted to the use of (111)-oriented substrates, while the diameters of as-grown III-V nanowires and quasi-1D heterostructures are still limited to above $50 \mathrm{~nm}$ by the spatial resolution limits of both EBL and plasma etching techniques (Motohisa et al., 2004) used to pattern the $\mathrm{SiO}_{2}$ mask.

Many of the above limitations are overcome in the case of nanowires self-assembled by the VLS mechanism (Wagner \& Ellis, 1964; Givargizov \& Chernov, 1973). Such mechanism rely on the ability of a suitable metal catalyst (usually $\mathrm{Au}$ ) nanoparticle (NP) to react and alloy at relatively low temperatures with one or more of the III-group metal elements. The catalyst $\mathrm{NP}$ acts thus as a solvent for the metal(s) in a manner similar to the case of liquid phase epitaxy. It is assumed that, when in contact with a nutrient vapour phase (referred to as the Vapour in the VLS acronym) and for temperatures above the Au/III-group eutectic composition melting point, the NP forms a supersaturated liquid alloy droplet (the Liquid), finally leading to the solid state precipitation, nucleation and subsequent growth of the semiconductor nanowire (the Solid). A detailed study on the VLS growth of InAs nanowires indicates however, that the $\mathrm{Au} / \mathrm{In}$ alloy droplet remains solid during the process (Dick et al., 2005), suggesting that the Au-catalysed growth of III-V nanowires may proceed through a Vapour-Solid-Solid (VSS) mechanism rather than through the VLS one. Despite these uncertainties, the acronym VLS is often retained in the nanowire literature to generally indicate a metal-catalyst assisted growth process.

A general characteristic of the VLS self-assembly of nanowires using MOVPE is that it relies on the existence of a kinetic hindrance to (planar) epitaxial growth (Seifert et al., 2004), a condition satisfied by growth at sufficiently low temperatures (typically below $500^{\circ} \mathrm{C}$ ). 
Noteworthy is also that the diameter of a VLS-grown semiconductor nanowire mimics the size of the original metal catalyst NP: nanowire diameters below $10 \mathrm{~nm}$ can be obtained by this method, provided that NPs of comparably small size are used in the process. No nanolithographic processing of the substrate is thus required by this technology, unless precise patterning of the nanowires onto the substrate is desired. In this respect, a major technological issue is the ability to precisely and reproducibly control the actual size and dispersion of the metal catalyst NPs, along with their density and homogeneity across the substrate surface.

\section{Au-catalyst NP technology}

A critical step in the fabrication of semiconductor nanowires by VLS self-assembly is the controlled preparation of the Au catalyst NPs on various substrates. Three methods have been reported to date in the literature: (a) Volmer-Weber self-organization from a thin metal film; (b) chemical synthesis in the form of colloidal solutions and subsequent deposition on the substrate; and (c) synthesis of aerosol Au NPs, their precise size-selection using electrostatic methods, and subsequent deposition on the substrate (Magnussson et al., 1999). The former method was first used by Hiruma and his colleagues at Hitachi Central Research Laboratory (Japan) for the VLS growth of GaAs and InAs nanowires (Hiruma et al., 1995). The second technique relies on the well-know and widely used methods of synthesizing metal-NP colloids based on solution chemical reactions (Jana et al., 2001; Walker et al., 2001). Finally, the third method is being employed by Samuelson and colleagues at the University of Lund (Sweden) for the VLS growth of III-V nanowires by chemical beam epitaxy and MOVPE (Ohlsson et al., 2001; Seifert et al., 2004). Examples of the first two methods are given in the following for preparation of Au NPs on crystalline semiconductor substrates.

\subsection{Au NPs from thin film self-organisation}

This is a straightforward method often used in the literature to fabricate Au NPs by the high temperature annealing of very thin (a few nm or less) UHV-evaporated films. Minimization of the material (surface plus strain) energy leads to the dewetting of the metal film and to the Volmer-Weber self-organization of the deposit into a dense distribution of NPs. A schematic of this method is shown in Fig. 1(a): a thin (typically $0.1 \div 10 \mathrm{~nm}$ ) Au film is evaporated under UHV conditions on suitably prepared substrates and afterwards annealed under inert gas flow. For relatively high annealing temperatures $\mathrm{Au}$ atoms gain sufficient surface mobility to rearrange the metal film into a dense array of NPs, thus minimizing its total energy. As the Au surface mobility depends on the interaction of the atoms with the underlying substrate material, the optimal annealing temperatures and the NP size and density will vary with the type of substrates. The case of Au on Si is specially interesting to study, as $\mathrm{Si}$ is a technologically important substrate for III-V nanowire fabrication (allowing the integration of future nanowire-based devices with Si microelectronics).

We studied the self-assembly process of Au thin fims on Si substrates. To this purpose, ptype (100)Si wafers were first degreased in iso-propanol vapours for $1 \mathrm{~h}$ for removal of any surface organic contaminants, subsequently etched at room temperature (RT) in a $\mathrm{NH}_{4} \mathrm{~F}: \mathrm{HF}$ solution for $6 \mathrm{~min}$ to eliminate the native Si-oxide layer from the substrate surface, rinsed in deionised water, and blown-dry under pure $\mathrm{N}_{2}$. The substrates were then immediately loaded in the UHV chamber of a Joule evaporator for deposition of the Au thin film. The evaporation rate was $0.02 \mathrm{~nm} / \mathrm{s}$ and the final Au film thickness was $2 \mathrm{~nm}$. After evaporation 


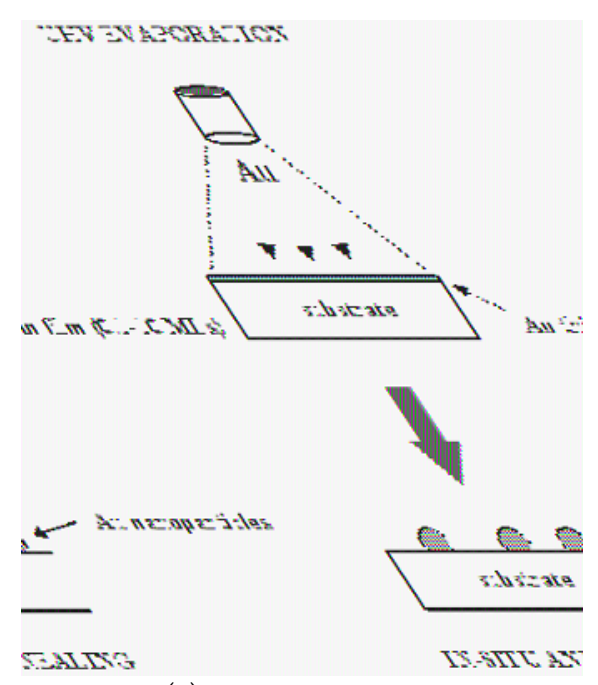

(a)

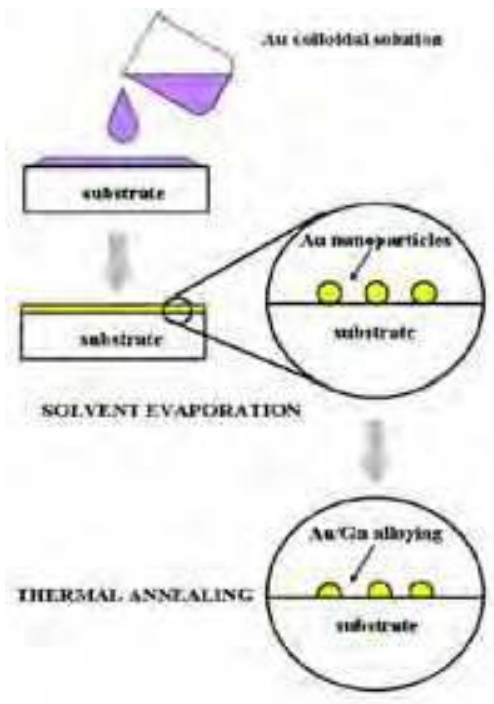

(b)

Fig. 1. Schematic of the Au NP fabrication/deposition steps onto a semiconductor substrate: (a) self-assembly from a UHV evaporated thin Au film; and (b) from colloidal Au solution.

the samples were loaded into the quartz chamber of a horizontal tubular resistance furnace for annealing under $6.0 \mathrm{~N}$ pure $\mathrm{N}_{2}$ atmosphere. Annealing experiments were performed for $20 \mathrm{~min}$ between $350^{\circ} \mathrm{C}$ and $814^{\circ} \mathrm{C}$, i.e. either just below or well above the reported melting point $\left(363^{\circ} \mathrm{C}\right)$ of the Au-Si eutectic composition; the sample temperature was increased from RT to the final value at a rate of about $10^{\circ} \mathrm{C} / \mathrm{sec}$. This treatment allows the Au film to selfassemble into a dense and uniform array of NPs across the entire Si surface. Fig. 2 shows the sample surface morphology before and after annealing at $814^{\circ} \mathrm{C}$. The as-deposited thin film evidences a granular morphology, but after annealing it self-organises into distinct NPs with average size in the $10 \div 30 \mathrm{~nm}$ range and surface densities around $1010 \div 10^{11} \mathrm{~cm}^{-2}$; the NP shape appears droplet-like, as shown by the $40^{\circ}$-tilted view field emission scanning electron microscopy (FE-SEM) image reported in the insert of Fig. 2(b). Glancing incidence X-ray diffraction (GIXRD) analyses of the as-annealed samples have shown that the NPs are composed of pure Au in its fcc phase, while diffraction experiments performed in the Bragg geometry showed that the Au NPs self-assembled at $814^{\circ} \mathrm{C}$ are mostly (111)-oriented with respect to the (100)-planes of Si (Spadavecchia et al., 2005). High resolution transmission electron microscopy (HR-TEM) analyses further clarified that the NPs are single crystalline lens-shaped nanoislands and, for samples annealed at $814^{\circ} \mathrm{C}$, the epitaxial relationships between the nanoislands and $\mathrm{Si}$ are uniquely defined as [001]Au\|[01 1 ]Si and [220]Au\|[311]Si (Piscopiello et al., 2008). In contrast, at lower annealing temperatures the nanoislands turn out to be randomly oriented. In all cases however, they appear partially embedded into the $\mathrm{Si}$ substrate, the $\mathrm{Au} / \mathrm{Si}$ interface being defined by smooth crystallographic facets, corresponding to the (111), (311), (711) and ( $\overline{1} 11$ ) Si-planes (see Fig. $3)$. For the epitaxially-grown nanoislands these planes are almost parallel to the (410), (110) and (160) planes of $\mathrm{Au}$, respectively. As a consequence, the Au lattice cell is rotated by $45^{\circ}$ 

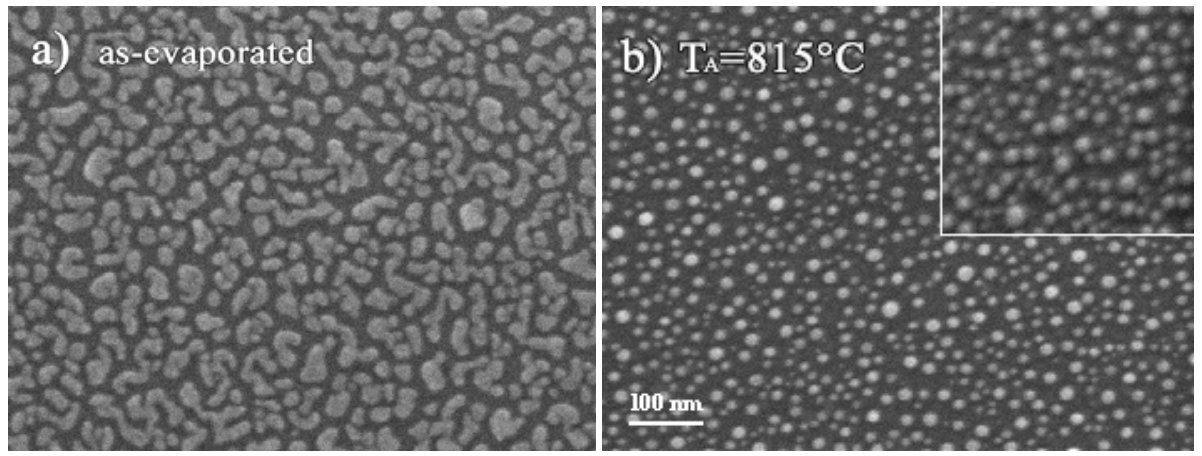

Fig. 2. FEG-SEM micrographs (150,000× magnification, plan-view) of 2-nm thin Au films on (100)Si (a) as-evaporated; and (b) after annealing at $814^{\circ} \mathrm{C}$ (inset represents a $40^{\circ}$-tilted view of the same sample). The marker in (b) represents $100 \mathrm{~nm}$ for both micrographs.

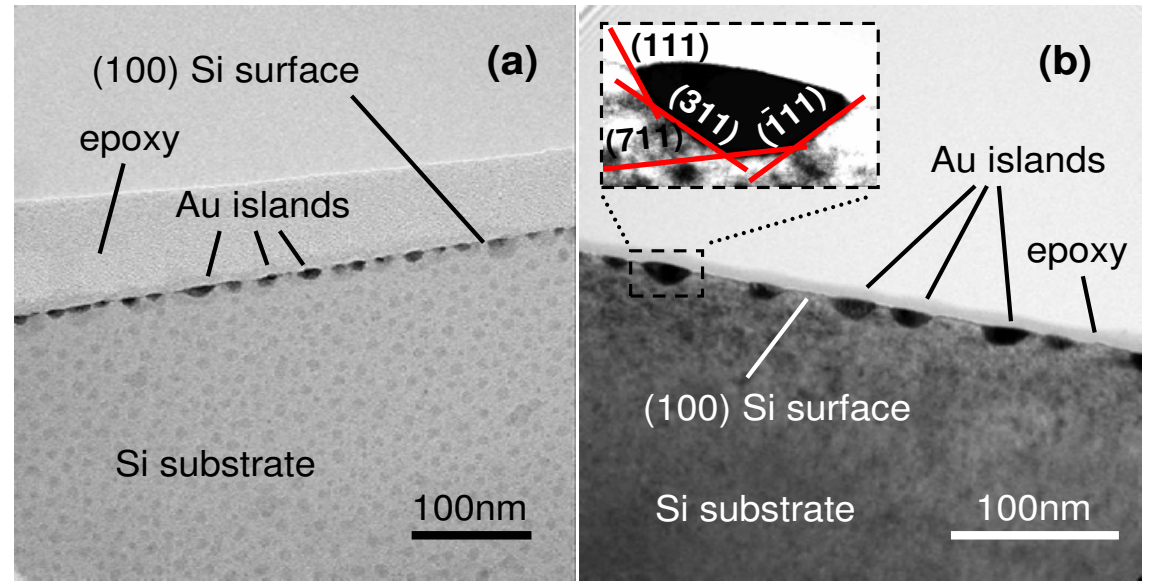

Fig. 3. Bright field cross-sectional TEM images of Au/Si samples annealed at (a) $350^{\circ} \mathrm{C}$, and (b) $814^{\circ} \mathrm{C}$, respectively. Au nanoislands are well visible (darker contrast) on the Si substrate surface. The inset in (b) shows an enlarged image of a Au nanoisland bound by well-defined crystallographic facets, corresponding to the (111), (311), (711) and (111) Si-planes.

and tilted by $21^{\circ}$ with respect to the Si lattice. The formation of such epitaxial interface minimizes the huge lattice mismatch (25\%) between $\mathrm{Au}$ and $\mathrm{Si}$ down to about $4 \%$; this, along with the small nanoisland size, allows the easier elastic relaxation of the Au lattice.

The growth of partially embedded Au nanoislands can be explained by the formation of a liquid $\mathrm{Si}-\mathrm{Au}$ alloy droplet during annealing at temperatures above the Au-Si eutectic melting point. ${ }^{1}$ The presence of residual oxygen and water $(<1 \mathrm{ppm})$ in the $\mathrm{N}_{2}$ gas used in

${ }^{1}$ In this respect, we stress the fact that the melting temperature of a nano-sized Au-Si eutectic alloy may well decrease below $350^{\circ} \mathrm{C}$, in the same way the melting temperature of pure $\mathrm{Au}$ is reduced from its bulk value in the case of metal nano-crystals below a few tens of nanometres. 
our experiments leads to oxidation of the $\mathrm{Si}$ atoms at the droplet surface and its evaporation in the form of $\mathrm{SiO}_{\mathrm{x}}$ molecules; in order to keep the $\mathrm{Si}$ concentration in the droplets constant (in accordance with the Au-Si phase diagram equilibrium conditions) more Si atoms must diffuse from the substrate into the droplets. This process make the Au-Si droplets sinking into the substrate. Upon cooling of the sample the droplets get supersaturated and redeposition of crystalline Si occurs, leading to the crystallisation of the pure Au nanoislands. During this step the facetted Au-Si interface of Fig. 3(b) thus forms. It is noteworthy that this process is expected for any substrate orientation, although the actual shape (faceting) of the resulting Au-Si nano-interface would be different from that observed for (100)Si. Furthermore, even the use of ultra-pure (to the level typically utilised for MOVPE) $\mathrm{H}_{2}$ may not completely prevent this phenomenon, if a residual level of moisture is somehow still present in the reactor chamber during the high temperature annealing stages.

Despite the complex process leading to the formation of $\mathrm{Au} \mathrm{NPs}$ on $\mathrm{Si}$, their size and distribution show a relatively weak dependence on annealing temperature. The average $\mathrm{Au}$ NP size and statistical dispersion across the (100)Si substrate surface can be determined quantitatively by the analysis of the sample FE-SEM micrographs. Fig. 4(a) reports a typical count histogram of the apparent Au NP diameters, as measured from a series of plan-view micrographs, for one of the $\mathrm{Au} /(100) \mathrm{Si}$ samples after annealing at $815^{\circ} \mathrm{C}$. Taking $\mathrm{D}$ as the $\mathrm{Au}$ NP diameter, its statistical distribution is best-described by the Gamma distribution function:

$$
P_{D_{0}, M}(D)=\frac{1}{\Gamma(M)}\left(\frac{M}{D_{0}}\right)^{M} \exp \left(-\frac{M}{D_{0}} D\right) D^{M-1}
$$

where $\mathrm{D}_{0}$ is the most probable NP diameter, $\mathrm{M}$ is the distribution shape parameter and $\Gamma$ is Euler's function. The distribution standard deviation is then given by $\sigma=\mathrm{D}_{0} / \mathrm{M}^{1 / 2}$. Fig. $4(\mathrm{~b})$ shows that for all samples $\mathrm{D}_{0}$ varies between $15 \mathrm{~nm}$ and $35 \mathrm{~nm}$, but the distribution relative standard deviations remain at $\sim 29 \%$.

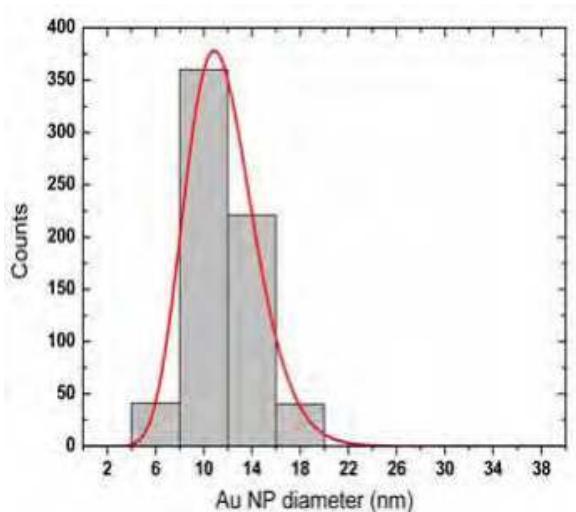

(a)

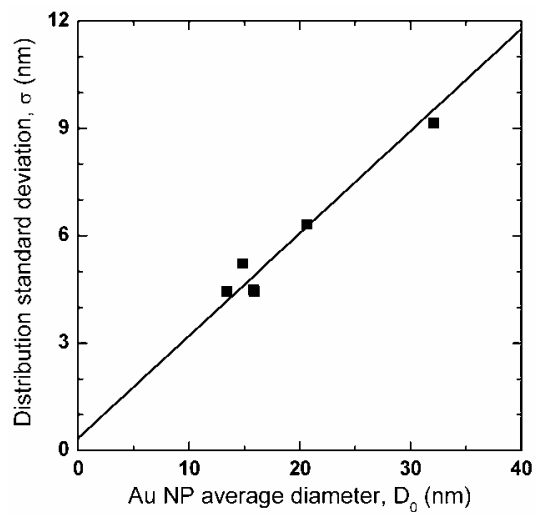

(b)

Fig. 4. (a) Count histogram of Au NP diameters for a 2-nm thin Au/(100)Si sample annealed at $815^{\circ} \mathrm{C}$. The red curve is the Gamma distribution function [Eq. (1)] best-fitting the data, with fitting parameters $\mathrm{D}_{0}=(11.6 \pm 0.02) \mathrm{nm}$ and $\mathrm{M}=16.1 \pm 0.2$; (b) the distribution standard deviations $(\sigma)$ as function of $\mathrm{D}_{0}$ for various samples annealed at $815^{\circ} \mathrm{C}$. The slope of the best-fitting solid line corresponds to a $29 \%$ average relative standard deviation. 


\subsection{Au NPs from colloidal solution}

The preparation of noble metal NPs in colloidal form can be obtained by a variety of chemical reaction methods (Turkevich et al., 1951; Jana et al., 2001; Walker et al., 2001). In particular, colloidal $\mathrm{Au}$ NPs can be prepared in aqueous solution by the reaction of tetrachloro-aurate $\left(\mathrm{HAuCl}_{4}\right)$ with sodium citrate (Turkevich et al., 1951) or other reagents containing more Au-philic molecules (such as thiols, etc.). The latter act as capping agents for the process, their concentration in the solution controlling the actual size of assynthesized $\mathrm{Au}$ NPs. As a matter of fact, changing the molar ratio between $\mathrm{HAuCl}_{4}$ and sodium citrate allows one to control the size of colloidal Au NPs anywhere within the 10-100 $\mathrm{nm}$ range. Colloidal NPs usually show a relatively narrow size dispersion and have been successfully used in the literature for the VLS growth of III-V nanowires by MOVPE (Khorenko et al., 2005; Paiano et al., 2006). In the following we report on the use of colloidal $\mathrm{Au}$ NPs in aqueous solution (synthesized as described above) for the VLS self-assembly of GaAs nanowires. The use of aqueous solutions is particularly suitable for applications with advanced epitaxial technologies, as the solvent (water) can be readily evaporated during preparation stages, moreover it is compatible with most standard wet-etching processes used for surface preparation of semiconductor wafers before growth.

Fig. 5(a) reports the linear optical absorption coefficient spectrum measured at RT for one such Au colloidal solution (with NP size around $23.4 \mathrm{~nm}$ and volume density around $10^{11}$ $\mathrm{cm}^{-3}$ ) with the strong plasmonic resonance of Au NPs peaked at around $518 \mathrm{~nm}$. The resonance shifts its peak wavelength position and width with the actual size of the NPs (Njoki et al., 2007); however, it is difficult to determine both the average size and dispersion of the NPs from the optical absorption spectra of colloidal solutions, especially for NP diameters in the $10 \div 30 \mathrm{~nm}$ range. The size dispersion of colloidal Au NPs can be more precisely studied by FE-SEM observations upon deposition of the NPs on a solid support. A typical result of the FE-SEM analysis is shown in Fig. 5(b): as in the case of Au NPs selfassembled onto Si (Sec. 3.1 above), the diameters of colloidal Au NPs appear dispersed according to a Gamma distribution function [Eq. (1)] (Nagao et al., 2004). By choosing the right $\mathrm{HAuCl}_{4}$ to sodium citrate molar ratio, Au NPs with average size down to $16 \mathrm{~nm}$ can be easily synthesised; the NP distribution relative dispersions range instead around 13-18\%.

A schematic of the deposition of colloidal Au NPs onto a substrate is illustrated in Fig. 1(b): the colloidal solution may be spin-dropped at RT on the surface of a freshly etched substrate. The solvent (water) is then evaporated by holding the sample on a hot $\left(70-80^{\circ} \mathrm{C}\right)$ plate (in air) for a few minutes. In order to attach the catalyst NPs on the surface, this is often treated by thoroughly rinsing in a poly-L-lysine aqueous solution (Hochbaum et al., 2005). The role of poly-L-lysine is to favour the adherence of Au NPs onto the substrate surface: the polymer possesses a net positive charge in aqueous solution at neutral $\mathrm{pH}$ and hence adsorbs onto the substrate surface. Consequently, the resulting poly-L-lysine film presents a positively charged group to the negatively charged (citrate anion capped) $\mathrm{Au}$ NPs, which attracts them to the surface. Rinsing the as-treated substrate into the colloidal solution finally leads to an even attachment of Au NPs onto the substrate surface. A possible drawback of poly-L-lysine is however, an increased carbon contamination of the surface.

As the deposition of colloidal NPs onto the substrate is generally realised in ambient atmosphere, this may easily lead to re-oxidation of the surface; the presence of surface oxides may prevent the crystallographic alignment of nanowires to the underlying substrate lattice. For this reason an in-situ (i.e., inside the MOVPE reactor chamber) $\mathrm{H}_{2}$ heat cleaning is 

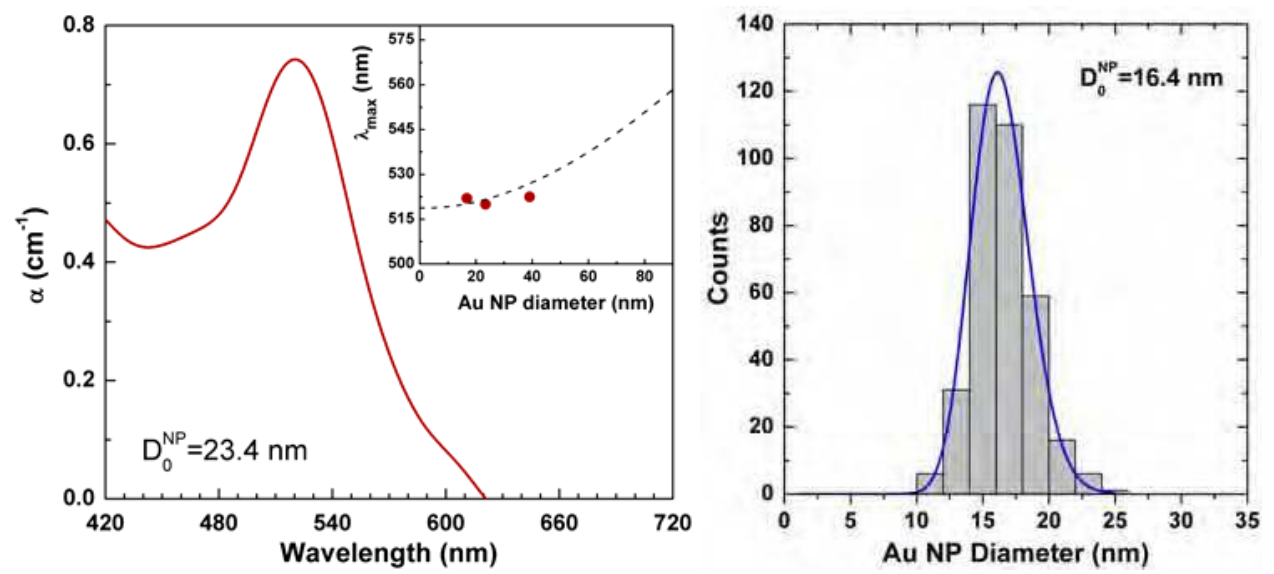

Fig. 5. (a) RT linear optical absorption coefficient of a colloidal Au NPs in aqueous solution around the plasmon resonance spectral region; the dashed curve in the inset shows the plasmon resonance peak wavelength as function of NP size (Njoki et al., 2007) along with present experimental data; (b) count histogram of Au NP diameters from one such colloidal solution, as-measured from FE-SEM observations. The blue solid curve is the best-fitting Gamma distribution function [Eq. (1)], with $\mathrm{D}_{0}=(16.40 \pm 0.07) \mathrm{nm}$ and $\mathrm{M}=57.4 \pm 3.6$. The distribution relative standard deviation is $13.2 \%$.

performed on the substrate before nanowire growth. This treatment additionally ensures the efficient pyrolysis and elimination of any organic contaminant (NP capping agents, poly-Llysine, etc.) brought onto the growth surface during its preparation with colloidal NPs. The actual temperature and vapour conditions of the $\mathrm{H}_{2}$ annealing step depends on the chemical nature of the substrate and thermal stability of its surface oxides. In the case of $\mathrm{Si}, \mathrm{H}_{2}$ heat cleaning at temperatures well above $900^{\circ} \mathrm{C}$ are necessary to fully desorb any residual silicon dioxide from the substrate surface (Moore et al., 2007), although annealing temperatures in the $600-700^{\circ} \mathrm{C}$ interval have been most often reported (Mårtensson et al., 2004; Khorenko et al., 2004) before III-V nanowire growth. In any case, these temperatures are well above the Au-Si eutectic melting point; therefore, phenomena similar to those observed for Au NPs self-assembled from a thin film (Sec. 3.1) should occur also for colloidal NPs annealed together with the $\mathrm{Si}$ substrate. On the contrary, the native oxides of $\mathrm{Ga}$ and As are much less stable than silicon dioxide and $\mathrm{H}_{2}$ treatment of $\mathrm{GaAs}$ at temperatures around $600-650^{\circ} \mathrm{C}$ are usually sufficient to reduce any trace of residual oxides from the substrate surface. GaAs annealing is usually performed under excess As in the vapour to prevent the material noncongruent evaporation. It has been claimed that under these As-excess conditions GaAs is stable against $\mathrm{Au}$ interaction (Dick et al., 2005); therefore, the behaviour of Au NPs on the surface of $\mathrm{GaAs}$ under high temperature annealing is expected to be entirely different from that observed for $\mathrm{Si}$.

In order to gain insights on this behaviour we studied the evolution of the colloidal Au NP size on the surface of GaAs upon annealing at $625^{\circ} \mathrm{C}$. To this purpose $(\overline{1} \overline{1} \overline{1}) \mathrm{B}$-oriented GaAs wafers were first degreased in iso-propanol vapours for $1 \mathrm{~h}$, subsequently etched at $\sim 40^{\circ} \mathrm{C}$ in a $\mathrm{H}_{2} \mathrm{SO}_{4}: \mathrm{H}_{2} \mathrm{O}_{2}: \mathrm{H}_{2} \mathrm{O}(4: 1: 2)$ solution for $8 \mathrm{~min}$, thoroughly washed in deionised water, and finally dried under pure $\mathrm{N}_{2}$. Colloidal NPs were then deposited on the freshly 
etched substrates as described above. To keep the GaAs surface as clean as possible, no poly-L-lysine was used to adhere the NPs onto the substrate. After loading the sample to the reactor chamber, its temperature was raised to $625^{\circ} \mathrm{C}$ under a $\mathrm{H}_{2}+$ tertiarybutylarsine (TBAs) atmosphere and annealing was then performed for $10 \mathrm{~min}$. The sample cool-down was also performed under the same $\mathrm{H}_{2}+$ TBAs flow. FE-SEM micrographs [Fig. 6(a)] of colloidal $\mathrm{Au}$ NPs after annealing were again studied for a quantitative analysis of their size dispersion. Fig. 6(b) shows a typical count histogram of the diameters for as-annealed NPs: noteworthy is that much larger diameters and larger distribution widths than those of initial colloidal NPs (Fig. 5) are observed. This effect can be ascribed to the well-known 'Ostwald ripening' mechanism, where smaller and less stable NPs shrink their size (and may even disappear) by losing $\mathrm{Au}$ atoms in favour of larger and more stable ones. As the mechanism is driven by the surface diffusion of $\mathrm{Au}$ atoms, sufficiently high annealing temperatures are required. Systematic experiments have shown that the effect sets in for temperatures above about $500^{\circ} \mathrm{C}$.

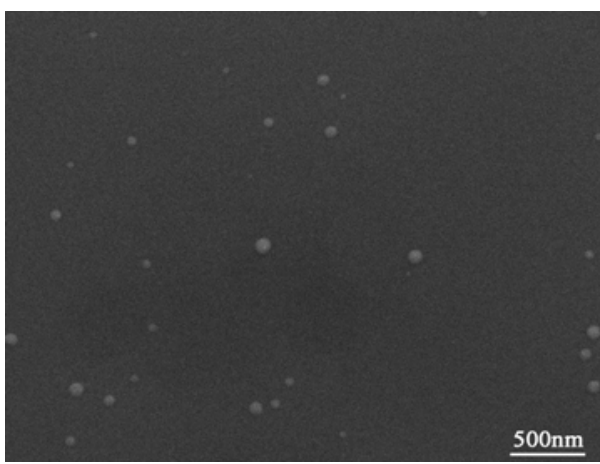

(a)

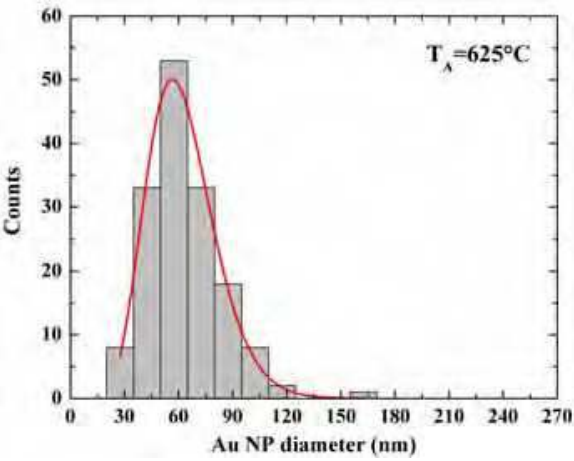

(b)

Fig. 6. (a) FE-SEM plan-view micrograph of colloidal Au NPs on the surface of a ( $\overline{1} \overline{1} \overline{1}) \mathrm{B}-$ GaAs substrate after annealing at $625^{\circ} \mathrm{C}$; (b) count histogram of NP diameters, as measured from the micrograph in (a); the red curve in (b) represents the Gamma function [Eq. (1)] best-fitting the experimental data, with $\mathrm{D}_{0}=(62.4 \pm 0.8) \mathrm{nm}$ and $\mathrm{M}=10.8 \pm 0.8$.

\subsection{Comparison between Au NPs from colloidal solutions and thin films}

It is useful to compare the average size and density of Au NPs observed after annealing on (100)Si and $(\overline{1} \overline{1} \overline{1}) \mathrm{B}-\mathrm{GaAs}$. In order to make a meaningful comparison we begin with analysing the characteristics of NPs self-assembled on the two substrates upon deposition of similar surface doses of $\mathrm{Au}$ atoms (equivalent to a film thickness around 1-2 nm). Fig. 7 reports both the average diameters and surface densities for Au NPs self-assembled as described in Secs. 3.1 and 3.2 - i.e. upon annealing at temperatures in the $500-625^{\circ} \mathrm{C}$ interval (for GaAs) and $815^{\circ} \mathrm{C}$ (for $\mathrm{Si}$ ). It appears that for the same deposited thickness much larger and less dense NPs self-assemble on GaAs than on $\mathrm{Si}$, despite the annealing temperatures used for Si are hundreds of degrees higher. This result can be ascribed to the higher surface diffusion of $\mathrm{Au}$ atoms on the surface of $\mathrm{GaAs}$ with respect to $\mathrm{Si}$, leading to a much more efficient Ostwald ripening of Au NPs for the former substrate. We showed elsewhere that $\mathrm{Au}$ NPs on (100)Si do show however, Ostwald ripening (Prete et al., 2007), but the strong 


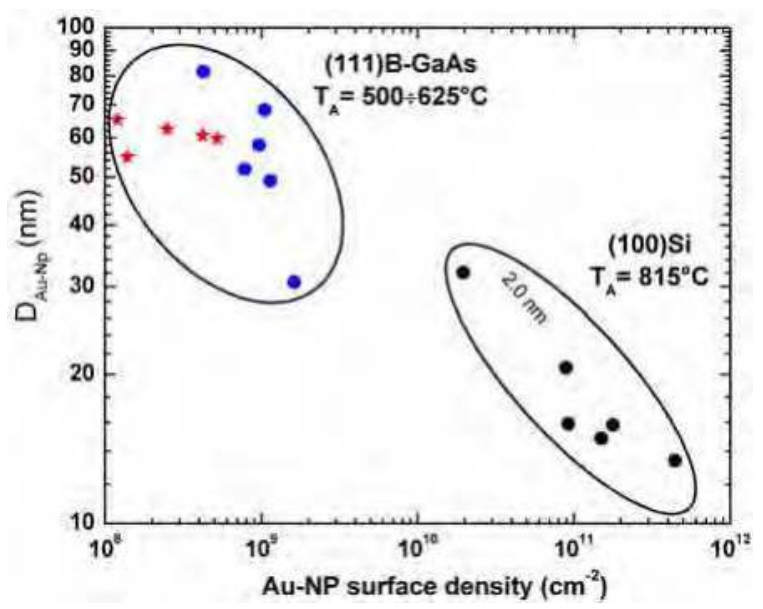

Fig. 7. Average Au NP diameters as function of surface density on ( $\overline{1} \overline{1} \overline{1}) \mathrm{B}-\mathrm{GaAs}$ and (100)Si substrates after annealing at temperatures between $500-625^{\circ} \mathrm{C}$ for $\mathrm{GaAs}$, and at $815^{\circ} \mathrm{C}$ for $\mathrm{Si}$. In the diagram, black and blue solid points refer to 1-2 $\mathrm{nm}$ Au deposition on GaAs $(\bullet)$ and Si $(\bullet)$, respectively, while the stars $(\star)$ refer to colloidal NPs deposited onto GaAs.

interaction of Au NPs with Si discussed in Sec. 3.1 clearly slows down the process with respect to GaAs. The Ostwald ripening appears also to affect the behaviour of colloidal $\mathrm{Au}$ NPs onto GaAs (Sec. 3.2), such that substrate annealing under standard MOVPE conditions results into huge changes of the NP size, size distribution and densities with respect to initial (as-deposited) values. As this phenomenon is intrinsic of the Au-GaAs interaction, the effect should hold as well for aerosol-produced Au NPs annealed under similar conditions.

\section{III-V nanowires grown by Au-catalyst assisted MOVPE}

In the mid 90's Hiruma and colleagues at Hitachi Central Research Laboratory (Japan) (Hiruma et al., 1995) were the first to demonstrate the VLS growth of III-V nanowires using Au NPs self-assembled from UHV evaporated thin metal films. Samuelson and co-workers of Lund University (Sweden) later on demonstrated the growth of free-standing GaAs nanowires using chemical beam epitaxy and size-selected aerosol Au NPs as metal catalysts (Ohlsson et al., 2001). The Au-catalysed MOVPE of GaAs, GaP, InAs, and InP nanowires was similarly demonstrated by the same group a few years later (Seifert et al., 2004). Today the MOVPE self-assembly of III-V nanowires is studied by several research groups, which however, in most cases use colloidal Au NPs as catalysts for the VLS growth.

To date the Au-catalyst assisted MOVPE of III-V nanowires has been extended to ternary alloys, such as GaAsP (Svensson et al., 2005), GaInP (Sköld et al., 2005), and InGaAs (Regolin et al., 2006), while only few data can yet be found on the catalyst-assisted MOVPE of AlGaAs nanowires (Lim et al., 2008). For these ternary alloys a major challenge is to growth nanowires with uniform composition along both their major axis and in the radial direction (Regolin et al., 2006; Kim et al., 2006; \& Lim et al., 2008). The MOVPE growth of nanowires with modulation of the material composition in either the axial or radial direction has been also demonstrated for a number of III-V systems. In particular, the growth of axially 
modulated nanostructures has been reported for the $\mathrm{GaP} / \mathrm{GaAsP}$ and $\mathrm{InP} / \mathrm{InAsP}$ systems, for whom examples of double-hetero-junction structures were reported (Svensson et al., 2005), while few data still exist on the growth and properties of AlGaAs/GaAs (Ouattara et al., 2007) and InGaAs/GaAs quasi-1D nanostructures. In these latter cases, the occurrence of group-III metal memory effects and instabilities within the catalyst NPs during growth lead to difficulties in achieving sharp compositional changes at the various interfaces within these structures (Kim et al., 2006; \& Ouattara et al., 2007).

The application of GaAs nanowires to novel nanophotonic devices is hindered by the proclivity of GaAs to readily oxidise in air, leading to the formation of surface states that reduce carrier lifetimes and quench the material optical emission. The growth of a shell using a large band-gap material around GaAs nanowires reduces the effects of surface states and enhances the radiative efficiency of GaAs nanowires; besides, changing the band-gap of the shell material allows to control the carrier confinement within the GaAs core and may also improve the optical confinement of the photons by acting as an optical cavity. The Aucatalysed growth and optical properties of GaAs/GaInP core-shell nanowires were first reported (Sköld et al., 2005), showing that alloy ordering of GaInP induces compositional and band-gap variations in the shell, leading to potential fluctuations within the shell and different strain states in the core. For these reasons, emphasis has been placed in the recent literature on the growth of GaAs/AlGaAs core-shell nanowire structures (Samuelson et al., 2004; Titova et al., 2006; Prete et al., 2008). The latter are of particular interest, as the GaAs$\mathrm{AlGaAs}$ materials combination represents a prototypical system in semiconductor optoelectronics. Also, the use of AlGaAs as shell material leads to almost strain-free nanowires, simplifying the analysis of their electronic/optical properties.

Despite the amount of work reported in the literature, systematic studies on the VLS selfassembly of III-V nanowires by MOVPE under different epitaxy conditions (substrate material and orientations, metal-catalyst preparation, type of precursors and purity, growth parameters, etc.) are still largely lacking. In particular, almost exclusive use of arsine $\left(\mathrm{AsH}_{3}\right)$ and phosphine as precursors of group-V elements was made in most of the studies above. Substitution of the toxic hydrides with alkyl-substituted arsine and phosphine molecules, besides leading to a safer process, may also improve the materials electronic properties (i.e. by reducing carbon and other unintentional impurity incorporation into the material). In the following, we report on the Au-catalysed growth of GaAs nanowires and GaAs$\mathrm{AlGaAs}$ core-shell nanostructures using the liquid precursor tertiarybutylarsine (TBAs).

\subsection{Growth of GaAs nanowires using TBAs}

The MOVPE growth of GaAs nanowires using TBAs has been previously reported in conjunction with either triethylgallium (TEGa) or trimethylgallium (TMGa), and pure $\mathrm{N}_{2}$ as carrier gas (Khorenko et al., 2005). Growth temperatures were limited to over $\sim 430^{\circ} \mathrm{C}$ in the case of TEGa and over $470^{\circ} \mathrm{C}$ for TMGa, i.e. above those $\left(\geq 400^{\circ} \mathrm{C}\right)$ reported using $\mathrm{AsH}_{3}$ (Seifert et al., 2004). As the VLS self-assembly of nanowires rely on the existence of a kinetic hindrance to (planar) growth, whose onset for $\mathrm{GaAs}$ is $\sim 480-500^{\circ} \mathrm{C}$, lower temperatures are essential to guarantee a good control over nanowire growth and shape. Furthermore, GaAs nanowires grown using TBAs+TEGa in $\mathrm{N}_{2}$ were heavily affected by bending and kinking (Khorenko et al., 2004; Khorenko et al., 2005), an effect ascribed to growth instability at the catalyst/nanowire interface. It is therefore of great importance to clarify the role of MOVPE conditions on the morphology and defects of as-grown GaAs nanowires using TBAs. 
GaAs nanowires were grown under $\mathrm{H}_{2}$ ambient by low (50 mbar) pressure MOVPE using an Aixtron reactor model AIX200 RD. TMGa and TBAs were used as Ga and As precursors, respectively. Semi-insulating ( $\overline{1} \overline{1} \overline{1}$ )B-oriented (within $\pm 0.01^{\circ}$ ) GaAs wafers were used as substrates. GaAs pieces were cut from wafers by cleavage along $\langle 110\rangle$ in-plane directions. Colloidal Au NPs, synthesized in aqueous solution, were deposited onto the freshly-etched substrates as described in Sec. 3.2. A rough estimate of as-deposited Au dose gives an equivalent $\mathrm{Au}$ film thickness around 0.1-0.5 nm; we notice that these values compare well with the thickness of UHV-evaporated Au films previously reported in the literature for the VLS growth of III-V nanowires (Hiruma et al., 1995). Immediately before growth the asdeposited substrates were annealed as described in Sec. 3.2. After ramping down the sample temperature to the final growth value, varied between $375^{\circ} \mathrm{C}$ and $525^{\circ} \mathrm{C}$, TMGa was admitted to the reactor chamber and the growth initiated. All growth runs were carried out under a $\mathrm{H}_{2}$ flow of $7.0 \mathrm{sl} / \mathrm{min}$, a TMGa molar fraction in the vapour of $3 \times 10^{-5}$, and a As:Ga precursor molar ratio around 7:1.

The above growth conditions allowed us to growth GaAs nanowires down to less than $400^{\circ} \mathrm{C}$ (Paiano et al., 2006). Fig. 8 shows the morphology of as-grown nanowires for different temperatures. The nanowires consist of straight GaAs segments epitaxially well-aligned in the substrate $[\overline{1} \overline{1} \overline{1}] \mathrm{B}$-direction, as confirmed by X-ray diffraction (XRD) measurements (see Sec. 4.2 below) and surface densities in the (1-6) $\times 10^{8} \mathrm{~cm}^{-2}$ interval. Furthermore, each nanowire shows a droplet at its tip, with size comparable to that observed for the Au NPs after their annealing at $625^{\circ} \mathrm{C}$. This confirms that the growth occurred through the VLS mechanism. Noteworthy, nanowires grown above $425^{\circ} \mathrm{C}$ show a substantial degree of tapering along the $[\overline{1} \overline{1} \overline{1}] \mathrm{B}$ growth direction, while constant diameter nanowires are obtained at lower temperatures. Plan-view FE-SEM observations of nanostructures grown above $425^{\circ} \mathrm{C}$ indicate that the tapering gives rise to a nanowire hexagonal section (Fig. 9); by comparing the directions of the hexagonal base edges with that of the substrate $\langle 110\rangle$ and $\langle 1 \overline{1} 0\rangle$ cleaved edges, it turned out that each couple of parallel base edges is aligned normal to one of the three equivalent $\langle\overline{2} 11\rangle$ in-plane GaAs directions.

Systematic FE-SEM plan-view observations of the samples have allowed a quantitative evaluation of the nanowire diameter $\mathrm{D}$ (taken as the major diagonal length of the nanowire hexagonal base). Fig. 10 reports a count histogram of base diameter values obtained from the analysis of several FE-SEM micrographs of a sample grown at $425^{\circ} \mathrm{C}$. It appears that the nanowires have a relatively narrow base diameter distribution, which can be best-fitted by a Gamma-distribution function [Eq. (1)]; this is no surprise as the nanowire dimensions mimic that of the Au-catalyst NPs that have generated them. A best-fit of the experimental data in Fig. 10 gives $D_{0}=(60.6 \pm 0.4) \mathrm{nm}$ and $M=28.2 \pm 0.9$, leading to a standard deviation of the base diameter distribution $\sigma_{\mathrm{NW}}=11.4 \mathrm{~nm}$ (corresponding to a $18.8 \%$ relative standard deviation). Significantly, the average diameter of the distribution closely matches that $\left[\mathrm{D}_{\mathrm{Au}}=(62.4 \pm 0.8)\right.$ $\mathrm{nm}$ ] of $\mathrm{Au}$ NPs after annealing: this confirms that negligible tapering of nanowires occurs at $425^{\circ} \mathrm{C}$. The same quantitative study was performed on nanowires grown between $375^{\circ} \mathrm{C}$ and $500^{\circ} \mathrm{C}$, allowing the precise estimate of the sample average base diameter $\mathrm{D}_{0}$ as function of temperature. The results of such analysis are reported in Fig. 11 for 10 min grown samples. It appears that growing below about $425^{\circ} \mathrm{C}$ ensures nanowires without tapering (i.e., with diameters almost coinciding with that of the Au NPs), while $\mathrm{D}_{0}$ increases exponentially with temperature above $425^{\circ} \mathrm{C}$. This latter finding indicates a kinetics-limited growth regime of the nanowire sidewalls. Fig. 10(b) further shows that tapered nanowires tends to have a larger diameter distribution, which linearly scales with the degree of tapering. 

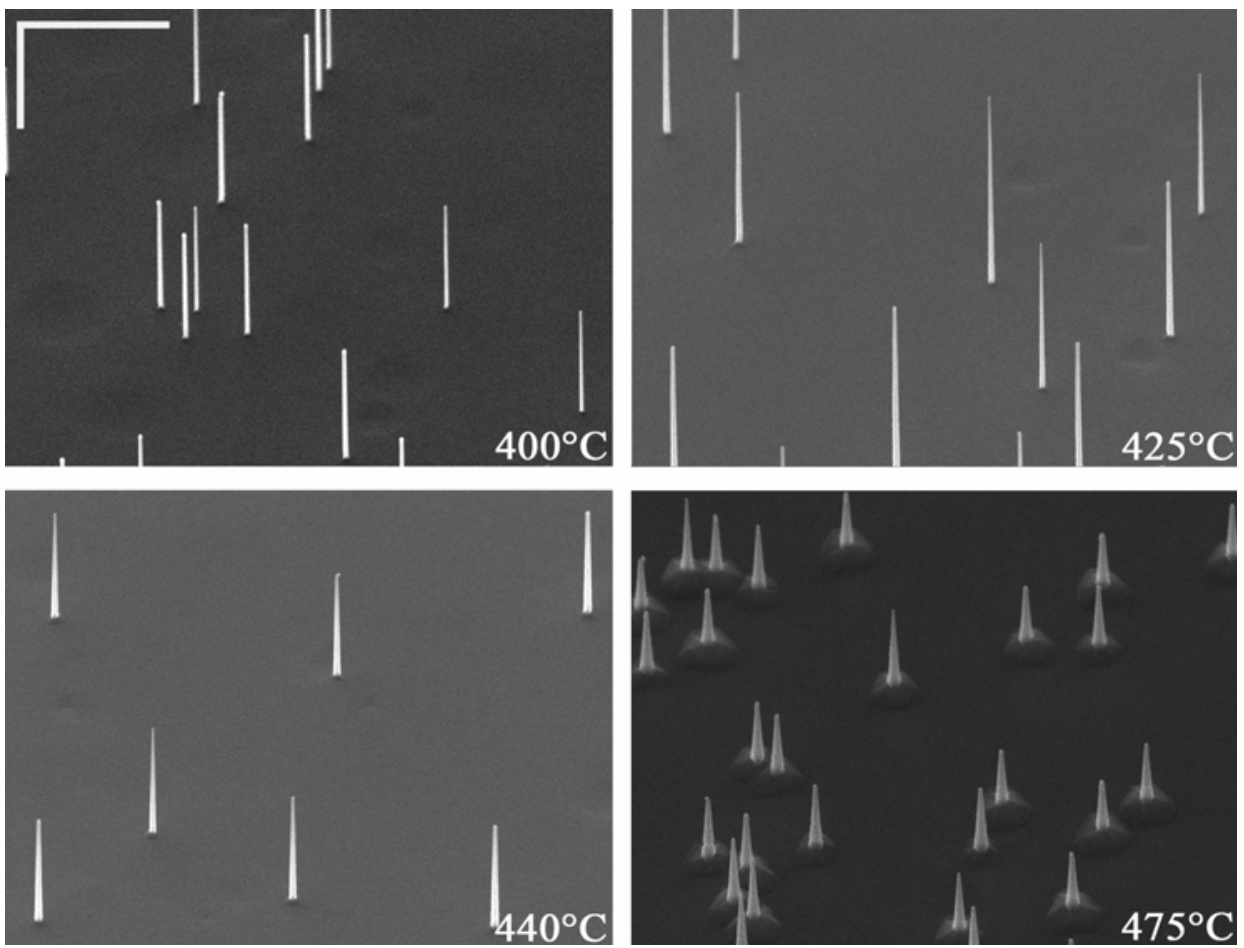

Fig. 8. FE-SEM micrographs (15,000× magnification, $45^{\circ}$ tilt view) of GaAs nanowires grown on $(\overline{1} \overline{1} \overline{1}) \mathrm{B} \mathrm{GaAs}$ at different temperatures. The growth time is $20 \mathrm{~min}$ for samples grown at $400^{\circ} \mathrm{C}$ and $425^{\circ} \mathrm{C}$, and $10 \mathrm{~min}$ for those grown at $440^{\circ} \mathrm{C}$ and $475^{\circ} \mathrm{C}$. Markers in the upper left micrograph represent $1 \mu \mathrm{m}$.
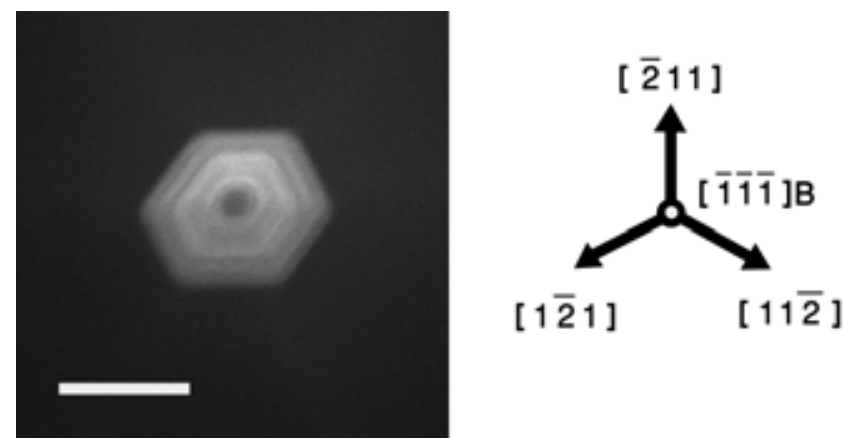

Fig. 9. FE-SEM micrograph (80,000× magnification, plan-view) of a [ $\overline{1} \overline{1} \overline{1}]$-aligned GaAs nanowire grown at $500^{\circ} \mathrm{C}$. The nanowire shows a hexagonal base, each couple of parallel base edges being aligned normal to one of the three equivalent $\langle\overline{2} 11\rangle$ substrate directions (as shown in the diagram on the left). A $60 \mathrm{~nm}$ diameter droplet is also observed at the nanowire tip. Marker in the micrograph represents $200 \mathrm{~nm}$. 

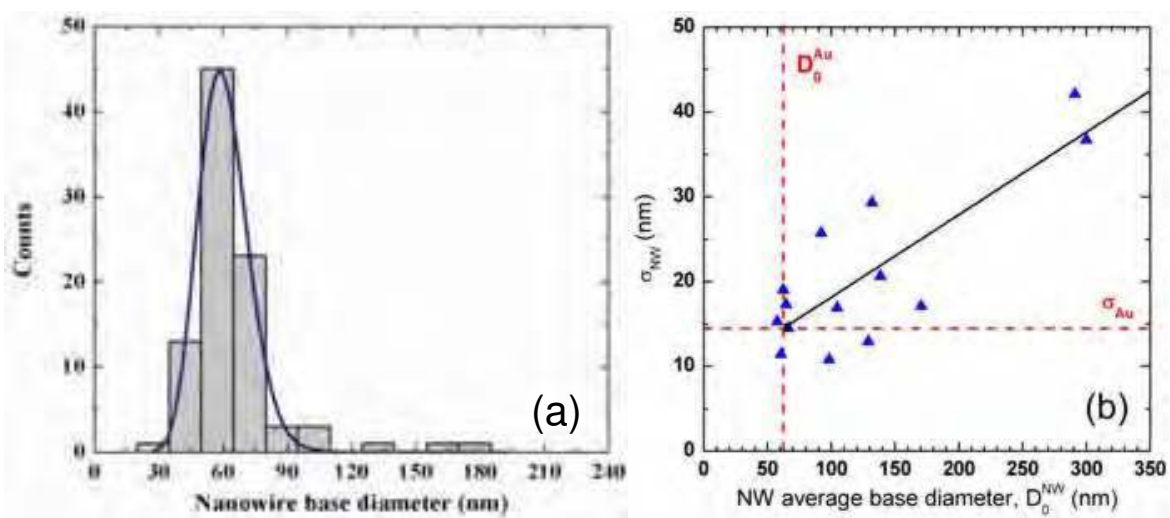

Fig. 10. (a) Count histogram of GaAs nanowire base diameters for a sample grown at $425^{\circ} \mathrm{C}$. The solid curve represents the Gamma-distribution function [Eq. (1)] best-fitting the data, with $\mathrm{D}_{0}=(60.6 \pm 0.4) \mathrm{nm}$ and shape parameter $\mathrm{M}=28.2 \pm 0.9$. (b) Variation of the base diameter distribution standard deviation with the nanowires average base diameter for samples grown at different temperatures. The red dashed lines indicate the (run-to-run) average diameter and distribution standard deviation of Au NPs annealed on ( $\overline{1} \overline{1} \overline{1}) \mathrm{B}-\mathrm{GaAs}$.

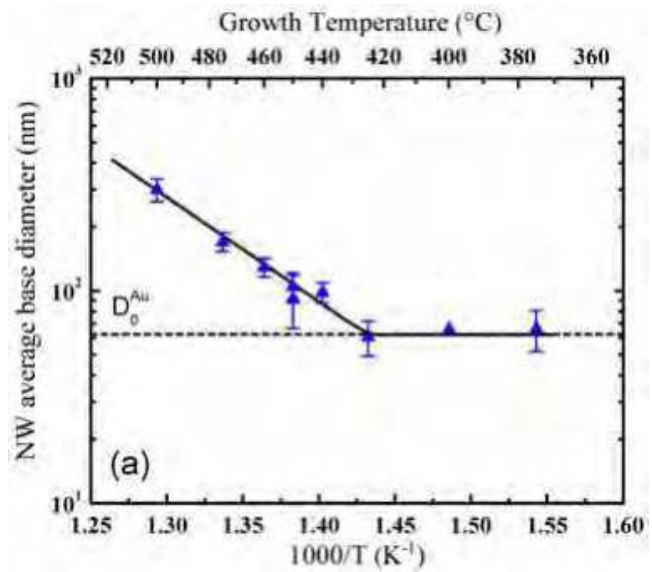

Fig. 11. Arrhenius plot of the nanowire average base diameters as function of the growth temperature. The horizontal dashed line represents the (run-to-run) average diameter $\mathrm{D}_{\mathrm{Au}}=62.4 \mathrm{~nm}$ of $\mathrm{Au}$ NPs after annealing at $625^{\circ} \mathrm{C}$. Solid lines are only guides for the eye.

To compare the growth kinetics of the material along the nanowire sidewalls with that in the $[\overline{1} \overline{1} \overline{1}] \mathrm{B}$ (axial) direction we measured the nanowire lengths of the same samples above. However, as the VLS growth rate of a nanowire along its axis is a non-linear function of the diameter (Johansson et al., 2005), we selected only those nanowires having tip diameter values around $D_{A u}=62 \mathrm{~nm}$ (within $\pm 8 \mathrm{~nm}$ ). The results are plotted in Fig. 12, where each data point is averaged over several tens of nanowires. It is first of all interesting to compare the as-measured axial nanowire growth rates with that of planar GaAs epilayers on the $(\overline{1} \overline{1} \overline{1}) \mathrm{B}$ 


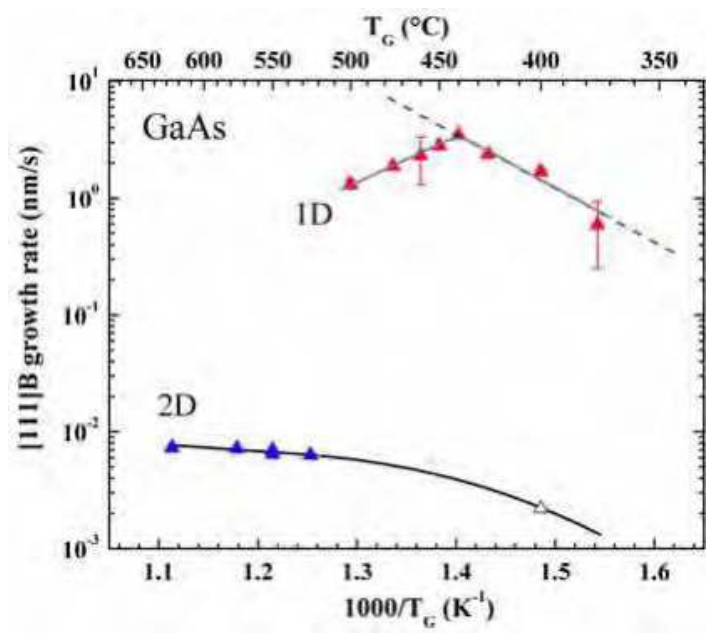

Fig. 12. Axial ( $\mathbf{\Delta})$ (for nanowires) and planar $(\mathbf{\Delta})$ [on the ( $\overline{1} \overline{1} \overline{1})$ B-oriented substrate surface] growth rate of GaAs as function of inverse growth temperature (Arrhenius plot). The open triangle $(\Delta)$ indicates the planar growth rate estimated at $400^{\circ} \mathrm{C}$. Solid lines are only an aid for the eye.

surface under identical vapour conditions: planar growth in the [ $\overline{1} \overline{1} \overline{1}] \mathrm{B}$ direction turns to be over two orders of magnitude lower than that of nanowires, confirming the existence of a kinetic hindrance to the GaAs planar growth also for TBAs. The nanowire growth in the axial direction shows a maximum of $3.44 \mathrm{~nm} / \mathrm{s}$ at around $440^{\circ} \mathrm{C}$; above this value the axial growth rate of the nanowires decreases due to the competing growth on the nanostructure sidewalls (tapering). Instead, below about $425^{\circ} \mathrm{C}$ almost no growth occurs at those surfaces. Under these conditions the growth appears thermally activated with an activation energy of $(20.7 \pm 3.2) \mathrm{kcal} / \mathrm{mol}$. This value is slightly above what reported for Au-catalysed GaAs nano-

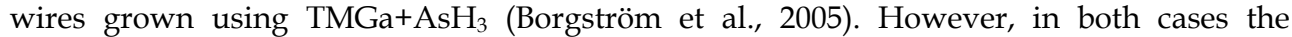
maximum growth rates occur at temperatures for which almost complete decomposition of TMGa is expected (DenBaars et al., 1986). Clearly, the use of TBAs in place of $\mathrm{AsH}_{3}$ does not greatly affect the pyrolysis efficiency of TMGa, if $\mathrm{H}_{2}$ is used as carrier gas; we notice however, that TBAs allows nanowire growth with good morphological quality for As:Ga molar ratios in the vapor (7:1) much lower than those (>27:1) typically reported for $\mathrm{AsH}_{3}$ (Seifert et al., 2004), a result of the lower decomposition temperatures of TBAs. Furthermore, our results indicate a substantial decrease of nanowire growth temperatures with respect to using $\mathrm{N}_{2}$ as carrier gas (Khorenko et al., 2005). In a purely surface-kinetics controlled growth regime, $\mathrm{H}_{2}$ has no role on the pyrolysis of TMGa, as the amount of adsorbed hydrogen on GaAs surface is known to be negligible (Qi et al., 1996); instead, $\mathrm{H}_{2}$ may enhance TMGa dissociation in the vapour through well-known hydrogen radical attack reactions.

\subsection{Crystallography of GaAs nanowires on (111)GaAs and (111)Si substrates}

The perfect epitaxial relationships of GaAs nanowires grown on $(\overline{1} \overline{1} \overline{1}) \mathrm{B}-\mathrm{GaAs}$ substrate is evidenced by the high-angle XRD spectrum reported in Fig. 13 for a sample grown at $450^{\circ} \mathrm{C}$; indeed, the spectrum shows only the (111), the quasi-forbidden (222) and the (333) 


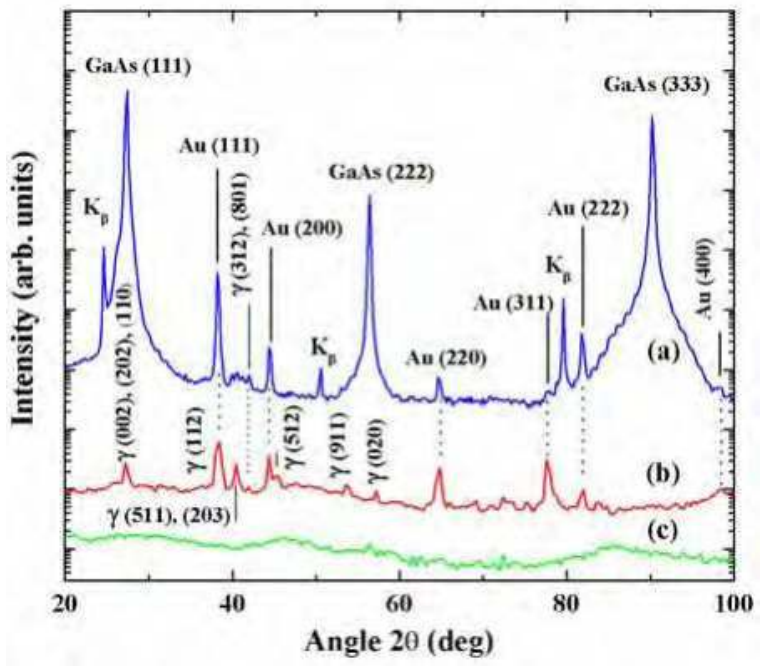

Fig. 13. (a) $\theta-2 \theta$ XRD, and (b) GIXRD spectra of a GaAs nanowires sample grown at $450^{\circ} \mathrm{C}$; (c) GIXRD spectrum of a bare ( $\overline{1} \overline{1} \overline{1})$ B-oriented GaAs substrate. Diffraction peaks belonging to $\mathrm{GaAs}, \mathrm{Au}$ and the $\mathrm{Au}_{2} \mathrm{Ga}$ alloy ( $\gamma$ phase) are indicated in the diagram. The spectra have been shifted along the intensity axis for clarity sake.

diffraction peaks of cubic GaAs, confirming that the nanowires are epitaxially well-aligned

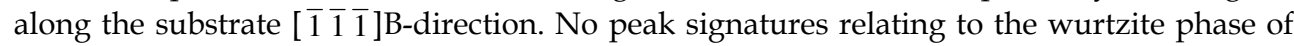
GaAs can be observed, indicating that the nanowires crystallise in the zinc-blend phase solely. Besides, several peaks which can be assigned to the fcc phase of $\mathrm{Au}$, are also observed in the spectrum, most of the Au being located at the nanowire tips. The Au peak positions in the $\theta-2 \theta$ spectrum agree with the angular values reported in the ICPDS powder diffraction database (ICPDS, 2000). However, the relative peak intensities are very different from that of powder-like material: the intensities of the Au (111) and (222) peaks are much enhanced, indicating that the (111)Au and (111)GaAs crystallographic planes are parallel to each other in most cases.

In addition, other very weak peaks occur in the angular region $39^{\circ}<2 \theta<42^{\circ}$ that cannot be attributed to either GaAs or Au. The exact crystallographic phase originating these peaks can be identified by the analysis of the GIXRD spectra. Noteworthy, the GIXRD pattern of the nanowire sample [curve (b) in Fig. 13] exhibits several weak diffraction peaks, not

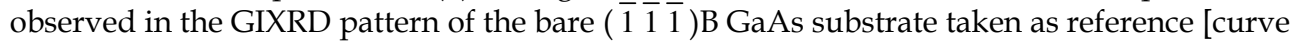
(c)]. Besides the expected relatively intense diffraction peaks of $\mathrm{Au}$, other peaks corresponding to the most intense of the diffraction peaks of the orthorhombic $\mathrm{Au}_{2} \mathrm{Ga}$ (ICPDS, 2000) appear in the spectrum at $27.2^{\circ}, 40.4^{\circ}, 42.0^{\circ}, 45.3^{\circ}, 53.6^{\circ}$ and $57.2^{\circ}$, a few others being likely shadowed by the superposition of $\mathrm{Au}$ peaks. The $\mathrm{Au}_{2} \mathrm{Ga}$ alloy (the so called $\gamma$ phase) is one of the Ga-rich alloys that may form in the Au-Ga binary system. Clearly, the alloy must be located at the Au-NP/nanowire interface.

The $\gamma$ phase is stable at temperatures below $349^{\circ} \mathrm{C}$ and its formation has been reported upon cooling below $370^{\circ} \mathrm{C}$ of a Au-Ga melted alloy (Zeng et al., 1987). This suggests that the catalyst NP at the tip of the nanowire is liquid at $450^{\circ} \mathrm{C}$, a temperature lower than that (470- 
$480^{\circ} \mathrm{C}$ ) generally expected for the formation of a Au-Ga melted alloy (Zeng et al., 1987; Dick et al., 2005). The formation of a saturated solid Au-Ga alloy (about 10 at- $\%$ Ga, $\alpha$ phase) at the Au-GaAs interface has been instead claimed (Dick et al., 2005) during nanowire growth up to $475^{\circ} \mathrm{C}$. On this basis, these authors proposed a VSS process, as the driving mechanism of the Au-catalyst assisted growth of III-V nanowires. One should however mention that the concentration of Ga reached in the Au-Ga alloy at the tip of the nanowire depends on the overall dynamic balance between Ga supply rate from the vapour, diffusion rate through the alloy and nanowire growth rate, which may change depending on actual MOVPE growth parameters. As a matter of fact, GIXRD measurements performed on nanowire samples grown at $400^{\circ} \mathrm{C}$ did not show the $\gamma$ phase peaks, suggesting that at lower temperatures the Au-Ga droplet may indeed remain solid.

GaAs nanowires were also grown on (111)Si wafers to compare their crystallography with that observed on ( $\overline{1} \overline{1} \overline{1}) \mathrm{B}-\mathrm{GaAs}$; to this purpose p-type (111)Si substrates were cleaned and etched as described in Sec. 3.1 and afterwards deposited with colloidal Au NPs having average size around $16.4 \mathrm{~nm}$; as-prepared samples were then annealed at $625^{\circ} \mathrm{C}$ under pure $\mathrm{H}_{2}$ flow for $20 \mathrm{~min}$. GaAs nanowires were grown at $450^{\circ} \mathrm{C}$ under MOVPE conditions similar to those used for the samples in Fig. 8. The typical morphology of GaAs nanowires grown on (111)Si is shown in Fig. 14: as expected, each nanowire appears tapered along its axis, indicating a substantial sidewall growth of the material; however, the nanowires show no preferential direction with respect to the substrate, few of them being also heavily kinked. Detailed study of the samples by FE-SEM observations do show that only a small fraction (1$2 \%$ ) of the nanowires is aligned with their axis normal to the substrate plane. Similar results have been also reported in the literature for GaAs nanowires grown on Si using TBAs and $\mathrm{N}_{2}$ as carrier gas (Khorenko et al., 2005). This is in striking contrast with other results reporting on the growth of well-aligned GaP (Mårtensson et al., 2004) and GaAs (Bao et al., 2008) nanowires on (111)Si. Clearly, actual conditions of Si surface preparation, the size of $\mathrm{Au}$ NPs and different procedures for their subsequent deposition and annealing may strongly influence the complex Au-Si interaction discussed in Sec. 3.1, so to adversely affect the VLS growth of III-V nanowires. More research is needed however, on this topic.

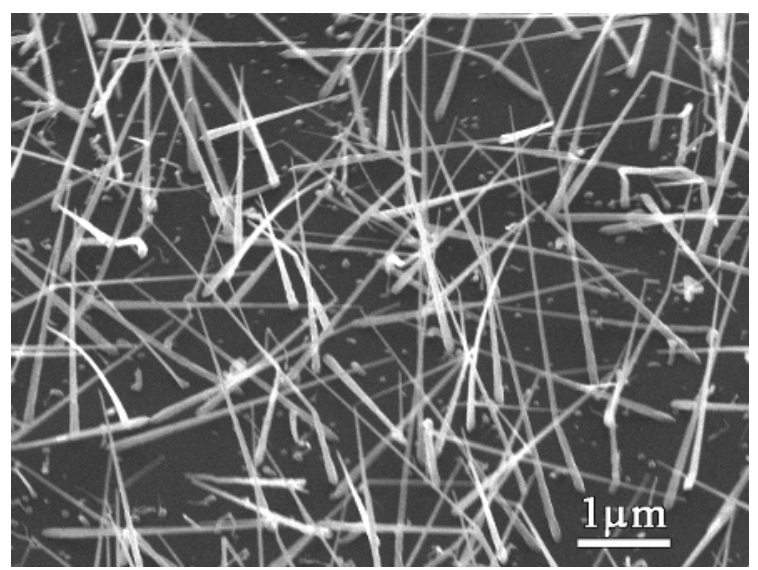

Fig. 14. FE-SEM micrograph (15,000× magnification, $45^{\circ}$ tilt view) of GaAs nanowires grown at $450^{\circ} \mathrm{C}$ on a (111)Si substrate. 


\subsection{Growth of GaAs-AIGaAs core-shell nanowires}

The growth of core-shell nanowires structures by MOVPE technology is easily realised by overgrowing the desired shell material around a nanowire core by conventional vapour epitaxy. This requires growth temperatures high enough to suppress the VLS mechanism in favour of a conformal (around the nanowire) deposition of the material. We have grown GaAs-AlGaAs core-shell nanowires on ( $\overline{1} \overline{1} \overline{1})$ B-GaAs substrates. In addition to TMGa and TBAs, trimethylaluminum (TMAl) was used as $\mathrm{Al}$ precursor. In these experiments the growth temperature of the GaAs core was kept at $400^{\circ} \mathrm{C}$ to ensure constant diameter nanowires throughout their entire lengths (see Sec. 4.1). Once the growth of the GaAs core was terminated, the substrate temperature was increased to $650{ }^{\circ} \mathrm{C}$ under a $\mathrm{H}_{2}+\mathrm{TBAs}$ for the $\mathrm{AlGaAs}$ shell overgrowth; to this purpose the $\mathrm{Al}$ fraction of the III-group metal precursors in the vapour $x^{v}=[\mathrm{TMAl}] /([\mathrm{TMAl}]+[\mathrm{TMGa}])$ was fixed at $\mathrm{x}^{\mathrm{v}}=0.50$. The shell growth time ranged between 4 and $10 \mathrm{~min}$. The nanostructures were grown by keeping the precursors V:III ratio in the vapour fixed to 5:1 for both core and shell and under a total $\mathrm{H}_{2}$ flow through the chamber of $7.0 \mathrm{sl} / \mathrm{min}$. Samples were cooled under a continuous $\mathrm{H}_{2}+\mathrm{TBAs}$ flow. Fig. 15(a) shows the morphology of as-grown GaAs/AlGaAs core-shell nanowires. They appear straight (kink-free) segments, with their major dimension running normal to the substrate $(\overline{1} \overline{1} \overline{1}) \mathrm{B}$ surface. As expected, the nanostructures have a constant diameter throughout their entire lengths, but for a small tapered section close-by their upper ends, where the original Au NPs (used to grow the GaAs core) are clearly visible. Plan-view FESEM observations showed that all core-shell nanowires have a hexagonal section (Fig. 16), with their side facets normal to one of the three equivalent in-plane [110] substrate directions. A similar result has been reported also for GaAs/AlGaAs core-shell nanowires grown by SAE-MOVPE on $\mathrm{SiO}_{2}$-patterned ( $\overline{1} \overline{1} \overline{1}$ )B-GaAs (Noborisaka et al., 2005b).

Fig. 15(b) shows a high-angle annular dark field (Z-contrast) image of a single GaAsAlGaAs core-shell nanowire recorded in a scanning transmission electron microscope. The contrast variation across the nanowire diameter is due to the different Ga composition of the

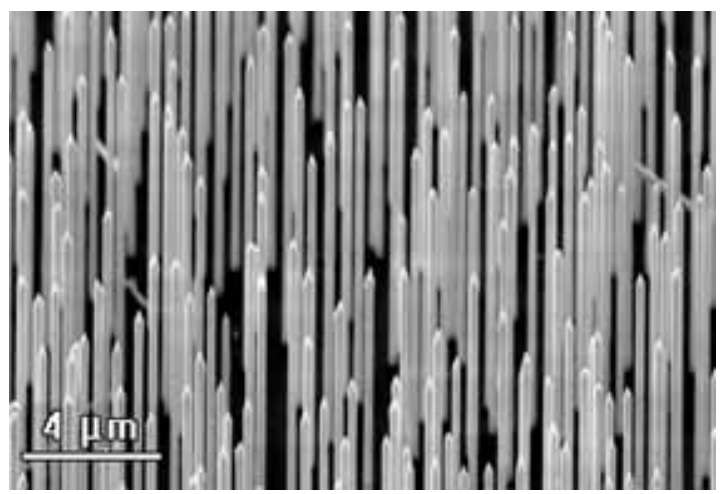

(a)

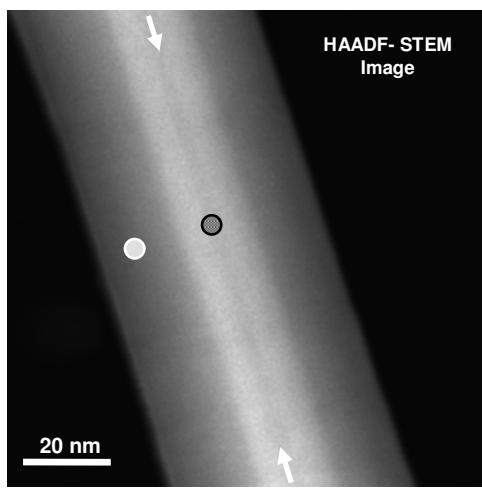

(b)

Fig. 15. (a) FE-SEM micrograph (21,000× magnification, $45^{\circ}$-tilt view) of a dense ensemble of GaAs-AlGaAs core-shell nanowires as-grown on the ( $\overline{1} \overline{1} \overline{1}) \mathrm{B}$ GaAs substrate. (b) Zcontrast image of a single GaAs-AlGaAs core-shell nanowire. The white and grey circles indicate regions from where EDS measurements were performed. The white arrows in the image indicate a central darker area inside the GaAs core region. 


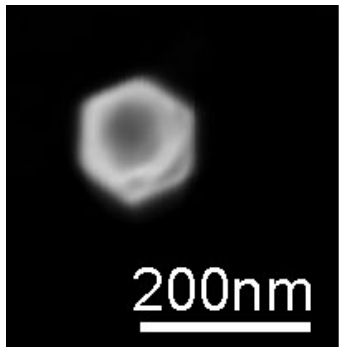

[110]

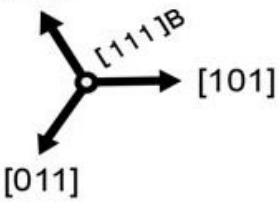

Fig. 16. FE-SEM micrograph of a single core-shell nanowire $(150,000 \times$ magnification, planview) showing its hexagonal section.

core (brighter) and the shell (darker) regions, as also indicated by X-ray energy dispersion spectroscopy (EDS) measurements performed at different positions along the same nanowire [indicated in Fig. 15(b)]. Analysis of EDS spectra collected from the shell region indicated an $\mathrm{Al}$ composition of the $\mathrm{AlGaAs}$ alloy $\mathrm{x}_{\mathrm{Al}}=0.32 \pm 0.02$. The Z-contrast image shows the presence of a darker region at the center of the GaAs core [indicated by the arrows in Fig. 15(b)]; in addition, a higher carbon (C) concentration was observed by EDS in the nanowire core than in the shell, most likely responsible for the lower Z-contrast signal observed in Fig 15(b). C is thus more efficiently incorporated into the GaAs nanowire core during VLS growth than in the AlGaAs shell under conventional MOVPE growth mode.

A quantitative analysis of FE-SEM plan-view images of as-grown nanowires recorded for the various samples allowed to estimate the GaAs core diameter and the corresponding AlGaAs shell thickness for each sample. Fig. 17(a) shows the size distribution of Au NPs sitting at the tips of the core-shell nanowires for a typical sample. Best-fitting the experimental data with the Gamma distribution function [Eq. (1)] gives a NP average diameter not far from the run-to-run average values reported in Sec. 4.1 for annealed Au NPs. As the Aucatalysed growth of $\mathrm{GaAs}$ at $400^{\circ} \mathrm{C}$ leads to cylindrical (untapered) GaAs nanowires, the above $\mathrm{Au} \mathrm{NP}$ values are thus assumed as representative of the nanostructure core size and

a)

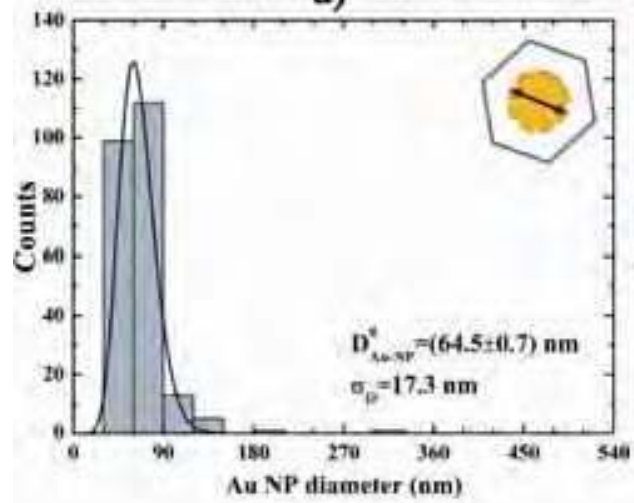

b)

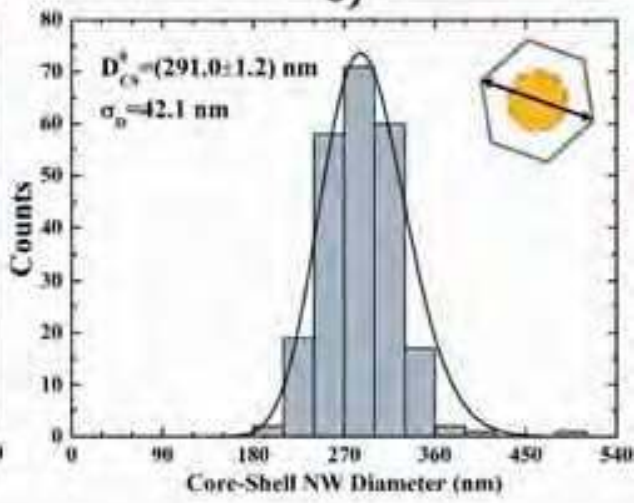

Fig. 17. Diameter count histograms of (a) Au NPs at the tips of core-shell nanowires, and (b) core-shell nanowires. The solid curves in both diagrams represent the Gamma distribution functions (Eq. 1) best-fitting the experimental data (fitting parameters shown in the graphs). 


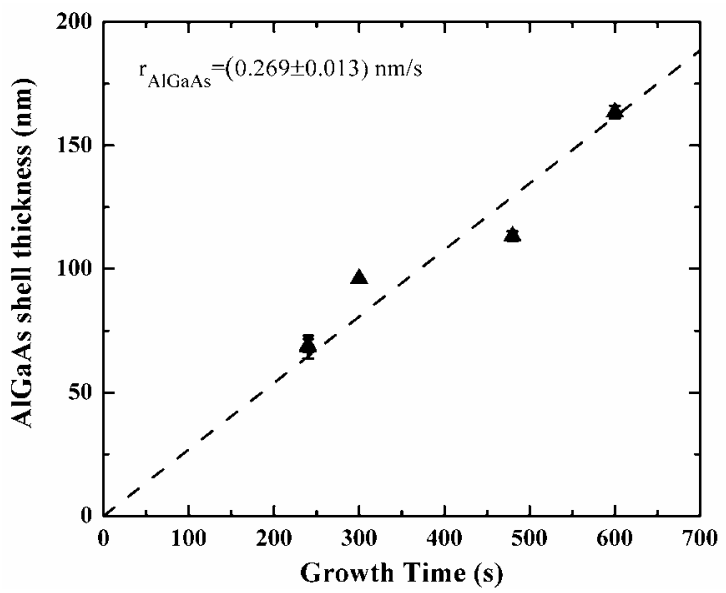

Fig. 18. Average thickness $(\boldsymbol{\Delta})$ of the AlGaAs shell as function of growth time. The dashed line is the linear best-fit of experimental points.

distribution width, respectively. Fig. 17(b) shows the diameter distribution of the same coreshell nanowires as in Fig. 17(a) along with its best-fitting Gamma distribution function: the nanowires, whose AlGaAs shell was grown for $8 \mathrm{~min}$, have an average diameter $D_{0}^{N W}=(291.0 \pm 1.2) \mathrm{nm}$ and a distribution standard deviation $\sigma_{\mathrm{D}}=42.1 \mathrm{~nm}$. The shell thickness for each core-shell nanowire can be then easily estimated. For the sample in Fig. 17 the average shell thickness is then $h_{\mathrm{AlGaAs}}=\left(D_{0}^{N W}-D_{0}^{N P}\right) / 2=(113 \pm 1) \mathrm{nm}$. Fig. 18 reports the average thickness of the AlGaAs shell as a function of the alloy growth time for different core-shell samples (shell thickness values were estimated in the same way as above): the AlGaAs thickness increases linearly with time, resulting in an alloy growth rate of 0.269 $\mathrm{nm} / \mathrm{s}$. This value must be compared with the $0.667 \mathrm{~nm} / \mathrm{s}$ growth rate of an AlGaAs epilayer deposited under identical conditions.

\subsection{Luminescence properties of GaAs-AIGaAs core-shell nanowires}

The radiative properties of GaAs-AlGaAs core-shell nanowires were determined by studying the photoluminescence (PL) of dense nanowire ensembles without removing them from their GaAs substrate. Fig. 19 shows the PL emissions measured at 7K under $532 \mathrm{~nm}$ laser excitation from a GaAs/AlGaAs core-shell sample, whose core and shell materials were grown for 20 and $10 \mathrm{~min}$, respectively. In order to discriminate between the nanowire emission and that of the substrate, PL spectra were recorded from different regions of the sample; in particular, the spectrum labelled (1) in the Figure refers to a region where no Au NPs were deposited, consisting of a (unintentionally-grown) planar AlGaAs/GaAs heterostructure, the AlGaAs epilayer being a few tenths of micron thick; spectrum (2) originates, instead, from a sample area where a dense ensemble of core-shell nanowires was grown. Given the laser beam spot size, this allowed to probe the collective PL emission of $10^{6}-10^{7}$ nanowires. The planar AlGaAs/GaAs region shows an intense PL emission due to radiative recombination from the GaAs substrate. Noteworthy, no signal was detectable above the GaAs band-edge, indicating negligible emission from the thin AlGaAs layer, which acts solely as passivation for the underlying GaAs crystal. 
An entirely different PL signal was recorded from the dense core-shell nanowire region: the PL emission, whose intensity is more than one order of magnitude weaker than that detected for the planar AlGaAs/GaAs region, is dominated by a broad band peaked at 1.49 $\mathrm{eV}$, showing a very broad tail on its low-energy side. Moreover, some additional broad and weak luminescence contributions can be observed between 1.52 and $2.05 \mathrm{eV}$; a Gaussian line-shape fitting of the PL spectrum [curve (3) in Fig. 19] demonstrates that this highenergy emission is made up of two very broad bands at around 1.67 and $1.90 \mathrm{eV}$, followed on their high-energy side by a relatively narrower (FWHM 49 meV) peak at $1.997 \mathrm{eV}$. These emissions weaken with decreasing the AlGaAs shell thickness in the nanowires; the dominant broad band below $1.52 \mathrm{eV}$ is observed instead for all samples, although its exact peak position and width may slightly change from sample to sample. High resolution cathodoluminescence (CL) measurements performed at $10 \mathrm{~K}$ on these core-shell nanowires after removal from their substrate confirmed the spectral features above, further allowing to compare the emission from dense ensembles of core-shell nanowires with that of single/few nanostructure(s) (Prete et al., 2008); also, comparison between secondary electron and monochromatic CL images of single nanowires further allowed to spatially resolve the main luminescence features, demonstrating that the $1.49 \mathrm{eV}$ emission originates from the GaAs core region of the nanowire, while those at $1.67 \mathrm{eV}, 1.90 \mathrm{eV}$ and $1.997 \mathrm{eV}$ are associated to the AlGaAs shell.

Temperature-dependent PL measurements (not reported here) have shown that the spectral feature at $1.997 \mathrm{eV}$ weakens and red-shifts with temperature until it vanishes above around $60 \mathrm{~K}$ (i.e. for $\mathrm{k}_{\mathrm{B}} \mathrm{T} \sim 5-6 \mathrm{meV}$ ). We assign this peak to the band-edge (excitonic) emission of the $\mathrm{AlGaAs}$ shell. This allows to determine the Al molar fraction in the alloy as $\mathrm{x}_{\mathrm{Al}}=0.34 \pm 0.01$ (Pavesi \& Guzzi, 1994; Wasilewski et al., 1997) in very good agreement with EDS

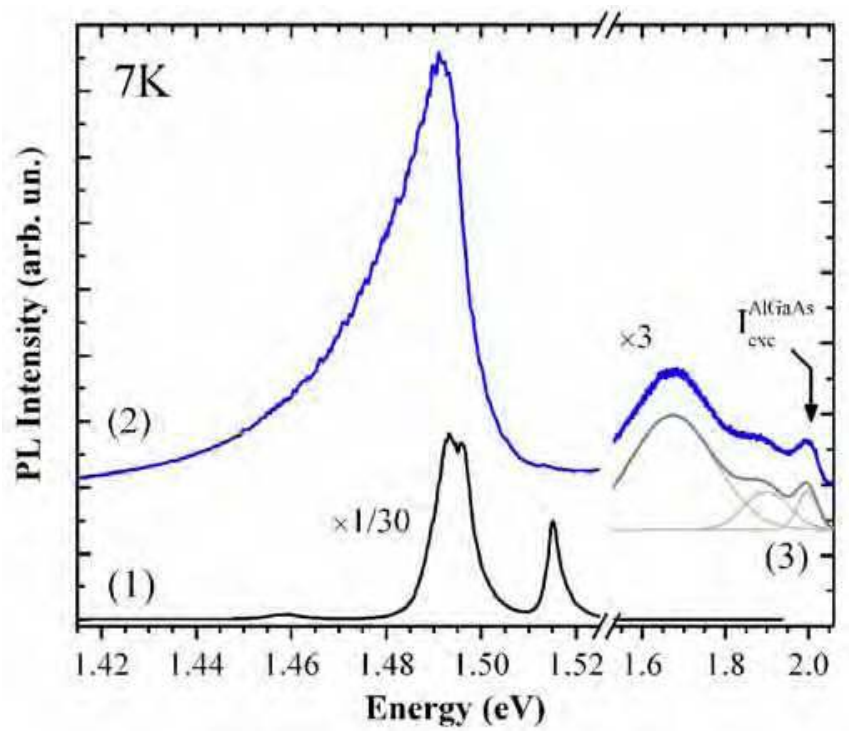

Fig. 19. PL spectra recorded at 7K from the GaAs/ AlGaAs core-shell nanostructures [curve (2)] and that of an ,equivalent' AlGaAs/GaAs planar structure [(curve (1)]. All spectra were recorded under a $532 \mathrm{~nm}$ laser line excitation. Excitation power for curve (2) was $\sim 5 \mathrm{~mW}$. 
measurements (Sec. 4.3). Preliminary Raman scattering experiments performed on single nanowires from the same samples confirmed that the AlGaAs composition is around 33\%. This strongly points towards the very good sample-to-sample and within-sample compositional homogeneity of the AlGaAs shell in present nanowires.

Noteworthy is that neither the broad band at around $1.67 \mathrm{eV}$ nor the one at $1.90 \mathrm{eV}$ can be observed under He-Ne laser excitation, i.e. for a laser photon energy just below the bandgap of the $\mathrm{Al}_{0.33} \mathrm{Ga}_{0.67} \mathrm{As}$ alloy indicating that both these bands originate from photoexcitation of the same $\mathrm{Al}_{0.33} \mathrm{Ga}_{0.67} \mathrm{As}$ alloy. The energy position of the weak $1.90 \mathrm{eV}$ band coincides fairly well with that of the so-called $\mathrm{D}_{1} \mathrm{~A}$ donor-acceptor pair recombination band observed in lightly Si-doped AlGaAs layers (Pavesi \& Guzzi, 1994), suggesting that the shell may contain a residual concentration of $\mathrm{Si}$ donors. Secondary ion mass spectrometry analysis of AlGaAs epilayers grown on (110)-oriented GaAs substrates under MOVPE conditions identical to those used for the nanowire shells confirmed that $\mathrm{Si}$ is indeed unintentionally incorporated in the material. The origin of $\mathrm{Si}$ is likely ascribable to the TMAl source used for present growth experiments, whose residual Si contamination is $\sim 0.8 \mathrm{ppm}$.

Finally, low temperature CL measurements performed on single nanostructures suggest that each nanowire has a slightly different core luminescence, its spectral peak position shifting from nanowire to nanowire within the same sample over a relatively narrow $(\sim 50 \mathrm{meV})$ energy interval (Prete et al., 2008). These energy shifts suggest the existence of a built-in electric field at the nanowire core-shell interface: indeed, such electric field may bend the materials conduction and valence bands, leading to the spatial separation of photogenerated carriers within the nanowire and to large energy shifts of the luminescence (Su et al., 2008). These effects require intense electric fields, corresponding to large space charge densities at the core-shell interface. The observation of a relatively high $\mathrm{C}$ signal within the nanowire core (Sec. 4.3) suggests that substantial carbon doping may occur into the GaAs core; this, together with the unintentional Si doping of the AlGaAs shell, may lead to the required space charge build-up at the GaAs-AlGaAs interface.

\section{Conclusions}

We briefly reviewed the current interests in free-standing III-V nanowires and major technological approaches being investigated for the synthesis, along with their limitations and advantages. In particular, self-assembly of these nanostructures by employing Aucatalyst assisted (VLS) MOVPE is currently considered a most promising technology in reason of its potentials in terms of materials control and scalability to industrial mass production of future nanowire-based devices.

Several methodologies are employed for the synthesis of Au catalyst NPs onto the surface of semiconductor substrates, among others self-assembly from thin metal films and deposition from colloidal Au solutions. These methods depend on metal catalyst surface diffusion on and interaction with the underlying substrate material; therefore, NP properties (i.e., size distribution, density, etc.), important to the VLS growth of nanowires, critically vary with preparation parameters. Examples of these effects have been reported for Au NPs on Si and GaAs substrates, annealed at temperatures similar to those used during MOVPE.

The growth of nanowires and related quasi-1D nanostructures has been demonstrated in the literature using Au-catalyst assisted MOVPE for most of III-V compounds. Despite the amount of work reported to date, a full understanding of the fundamental mechanism of 
VLS self-assembly of III-V nanowires and the role of growth parameters on the physical properties of as-grown nanostructures is still largely lacking.

In this Chapter, the growth and some of the physical properties (size, morphology, structure, luminescence, impurities) of GaAs and GaAs-AlGaAs core-shell nanowires using colloidal $\mathrm{Au}$ NPs as catalysts and TBAs in substitution of $\mathrm{AsH}_{3}$ is reported as case study. Good control over the size, shape and compositional uniformity of these nanostructures is demonstrated for epitaxially oriented nanowires; core-shell nanowires show strong luminescence from both their core and shell materials, but their origins remain to be fully understood, along with the role of MOVPE conditions and unintentional impurities (especially carbon) on the observed properties.

\section{Acknowledgements}

The authors would like to acknowledge F. Marzo, I. Miccoli, and P. Paiano (of University of Salento, Lecce, Italy), E. Piscopiello, and L. Tapfer (of Centro Ricerche ENEA, Brindisi, Italy), as well as L. Lazzarini, and G. Salviati (of IMEM-CNR, Parma, Italy) for their collaboration to this work and the many discussions. The partial support of the Italian Ministry of Foreign Affairs (MAE) through the Italy-Japan Significant Bilateral Project: "Nanocharacterization of nanowires, nanomagnets and laser diodes for sensors, opto-electronics and data storage" is also acknowledged.

\section{References}

Bao, X.-Y.; Soci, C.; Susac, D.; Bratvold, J.; Aplin D.P.R.; Wei, W.: Chen, C.-Y.; Dayeh S.A.; Kavanagh K.L. \& Wang, D. (2008). Heteroepitaxial growth of vertical GaAs nanowires on $\mathrm{Si}$ (111) substrates by metal-organic chemical vapor deposition. Nano Lett., 8, 11, (November 2008) 3755-3760, ISSN: 0028-0836.

Bjork, M.T.; Ohlsson, B.J.; Thelander, C.; Persson, A.I.; Deppert, K.; Wallenberg, L.R. \& Samuelson, L. (2002). Nanowire resonant tunneling diodes, Appl. Phys. Lett., 81, (December 2002) 4458-4460, ISSN: 0003-6951.

Borgström, M.; Deppert, K.; Samuelson, L. \& Seifert, W. (2004). Size- and shape-controlled GaAs nano-whiskers grown by MOVPE: a growth study. el Cryst. Growth 260 (January 2004) 18-22, ISSN: 0022-0248.

Borgström, M.T.; Zwiller, V.; Müller, E. \& Imamoglu, A. (2005). Optically Bright Quantum Dots in Single Nanowires. Nano Lett. 5, (June 2005) 1439-1443, ISSN: 0028-0836.

Colombo, C.; Hei, M.; Grätzel, M. \& Fontcuberta i Morral, A. (2009). Gallium Arsenide p-i-n Radial Structures for Photovoltaic Applications. Appl. Phys. Lett., 94, (April 2009) 173108,1-3, ISSN: 0003-6951.

DenBaars, S. P.; Maa, B. Y.; Dapkus, P. D.; Danner, A. D. \& Lee, H. C. (1986). Homogeneous and heterogeneous thermal decomposition rates of trimethylgallium and arsine and their relevance to the growth of GaAs by MOCVD. I Cryst. Growth 77 (September 1986) 188-193, ISSN: 0022-0248.

Dick, K.A.; Deppert, K.; Karlsson, L.S.; Wallenberg, L.R.; Samuelson, L. \& Seifert, W. (2005). A new understanding of Au-assisted growth of III-V semiconductor nanowires. Adv. Funct. Mater., 15, (October 2005) 1603-1610, ISSN: 1616-301X. 
Givargizov, E. I. \& Chernov, A.A. (1973). Rate of whisker growth by the vapor-liquid-crystal mechanism and the role of surface energy. Sov. Phys. Crystall., 18, (July-August 1973) 89-92, ISSN: 0038-5638.

Goto, H.; Nosaki, K.; Tomioka, K.; Hara, S.; Hiruma, K.; Motohisa, J. \& Fukui, T. (2009). Growth of core-shell InP nanowires for photovoltaic application by selective-area metal organic vapor phase epitaxy. Appl. Phys. Expr., 2, (February 2009) 035004, 1-3, ISSN: 1882-0778 (print), 1882-0786 (on-line)

Hiruma, K.; Yazawa, M.; Katsuyama, T.; Ogawa, K.; Haraguchi, K.; Koguchi, M.; \& Kakibayashi, H. (1995). Growth and optical properties of nanometer-scale GaAs and InAs whiskers. I Appl. Phys., 77, 2, (January 1995) 447-462, ISSN: 0021-8979 (print), 1089-7550 (online).

Hochbaum, A. I. ; Fan, R.; Hui, R. \& Yang, P.(2005). Controlled growth of Si nanowire arrays for device integration. Nano Lett. 5 (January 2005) 457- 460, ISSN: 0028-0836.

ICPDS-International Centre for Powder Diffraction Data (2000). PDF Cards no. 04-0784 \& no. 29-0619.

Jana, N. R.; Gearheart, L. \& Murphy, C. J. (2001). Wet chemical synthesis of high aspect ratio cylindrical gold nanorods. I Phys. Chem. B 105 (April 2001) 4065-4067, ISSN (printed): 1089-5647. ISSN (electronic): 1520-5207.

Johansson, J.; Svensson, C. P. T.; Mårtensson, T.; Samuelson, L. \& Seifert, W. (2005). Mass transport model for semiconductor nanowire growth. I Phys. Chem. B 109 (June 2005) 13567-13571, ISSN (printed): 1089-5647. ISSN (electronic): 1520-5207.

Kapon, E. (1994). Lateral patterning of quantum well heterostructures by growth on nonplanar substrates, in: Semiconductors and Semimetals, Epitaxial Microstructures, 40, Gossard A.C. (Ed.), 259-336, Academic Press, Inc. Published by Elsevier Ltd, ISBN: 9780127521404, Boston (USA).

Khorenko, V.; Regolin, I.; Neumann, S.; Prost, W. \& Tegude, F.-J. (2004). Photoluminescence of GaAs nanowhiskers grown on Si substrate. Appl. Phys. Lett., 85, 26, (December 2004) 6407-6408, ISSN: 0003-6951.

Khorenko, V.; Regolin, I.; Neumann, S.; Do, Q.; Prost, T.W. \& Tegude, F.-J. (2005). Characterisation of GaAs nanowhiskers grown on GaAs and Si substrates, Proceedings of 2005 Intern. Conf. on Indium Phosphide and Related Materials, IEEE Conf. Procs. 363-366, ISBN: 0-7803-8891 -7 , Glasgow, Scotland, (UK), May 2005, Institute of Electrical and Electronics Engineers Inc.

Kim, Y.; Joyce, H. J.; Gao, Q.; Tan, H. H.; Jagadish, C.; Paladugu, M.; Zou, J. \& Suvorova, A. A. (2006). Influence of nanowire density on the shape and optical properties of ternary InGaAs nanowires. Nano Lett. 6, (February 2006) 599-604, ISSN: 0028-0836.

Lim, S.K.; Tambe, M.J.; Brewster, M.M. \& Gradečak, S. (2008). Controlled growth of ternary alloy nanowires using metalorganic chemical vapor deposition. Nano Lett., 8, 5, (April 2008) 1386-1392, ISSN: 0028-0836.

Magnusson, M.H.; Deppert, K.; Malm, J.-O.; Bovin, J.-O. \& Samuelson L. (1999) Size-selected gold nanoparticles by aerosol technology. Nanostruct. Mater., 12, 1-4, (October 1999) 45-48, ISSN: 1359-6454.

Mårtensson, T.; Svensson, C.P.T.; Wacaser, B.A.; Larsson, M.W.; Seifert, W.; Deppert, K.; Gustafsson, A.; Wallenberg, L.R. \& Samuelson, L. (2004). Epitaxial III-V nanowires on silicon. Nano Lett., 4, 10, (September 2004) 1987-1990, ISSN: 0028-0836. 
Mohan, P.; Motohisa, J. \& Fukui, T. (2006). Fabrication of InP/InAs/InP core-multishell heterostructure nanowires by selective area metalorganic vapor phase epitaxy. Appl. Phys. Lett., 88, (March 2006) 133105,1-3, ISSN: 0003-6951.

Moore, J.C.; Skrobiszewski, J.L. \& Baski A.A. (2007). Sublimation behavior of $\mathrm{SiO}_{2}$ from lowand high-index silicon surfaces. I Vac. Sci. Technol. A, 25, 4, (July 2007) 812-815, ISSN: 0734-2101 (print) 1520-8559 (online).

Motohisa, J.; Noborisaka, J.; Takeda, J.; Inari, M. \& Fukui T. (2004). Catalyst-free selectivearea MOVPE of semiconductor nanowires on (111)B oriented substrates. J. Cryst. Growth, 272 (December 2004), 180-185, ISSN: 0022-0248.

Nagao, O.; Harada, G.; Sugawara, T.; Sasaki, A. \& Ito, Y. (2004). Small-angle X-ray Scattering method to determine the size distribution of gold nanoparticles chemisorbed by thiol ligands. .pn. el Appl. Phys., Part 1, 43, (November 2004) 7742-7746, ISSN (print): 0021-4922, ISSN (electronic): 1347-4065.

Njoki, P.N.; Lim, I-Im S.; Mott, D.; Park, H.-Y.; Khan, B.; Mishra, S.; Sujakumar, R.; Luo, J. \& Zhong C.-J. (2007). Size correlation of optical and spectroscopic properties for gold nanoparticles. Il Phys. Chem. C, 111, 40, (September 2007) 14664-14669, ISSN (print): 1932-7447, ISSN(electronic): 1932-7455.

Noborisaka, J.; Motohisa, J.; \& Fukui, T. (2005a). Catalyst-free growth of GaAs nanowires by selective-area metalorganic vapor-phase epitaxy. Appl. Phys. Lett., 86, (May 2005) 213102, 1-3, ISSN: 0003-6951.

Noborisaka, J.; Motohisa J.; Hara, S. \& Fukui, T (2005b). Fabrication and characterization of freestanding GaAs/AlGaAs core-shell nanowires and AlGaAs nanotubes by using selective-area metalorganic vapor phase epitaxy. Appl. Phys. Lett. 87, (August 2005) 093109, 1-3, ISSN: 0003-6951.

Nötzel, R. \& Ploog, K.H. (2000). Quantum wires and quantum dots on high-index substrates. Phys. E, 8, (August 2000) 117-124, ISSN: 1386-9477.

Ohlsson, B.J.; Björk, M.T.; Magnusson, M.H.; Deppert, K.; Samuelson, L. \& Wallenberg, L.R. (2001). Size-, shape-, and position-controlled GaAs nano-whiskers. Appl. Phys. Lett. , 79, 20, (November 2001) 3335-3337, ISSN: 0003-6951.

Ouattara, L.; Mikkelsen, A.; Skölld, N.; Eriksson, J.; Knaapen, T.; Ćavar, E.; Seifert, W.; Samuelson, L. \& Lundgren, E. (2007). GaAs/AlGaAs nanowire heterostructures studied by scanning tunneling microscopy. Nano Lett., 7, 9, (August 2007) 28592864, ISSN: 0028-0836.

Paiano, P.; Prete, P.; Lovergine, N. \& Mancini, A. M. (2006). Size and shape control of GaAs nanowires grown by metalorganic vapor phase epitaxy using tertiarybutylarsine. J Appl. Phys. 100 (November 2006) 094305, 1-4, ISSN: 0021-8979 (print), 1089-7550 (online).

Paiano, P.; Prete, P.; Speiser, E.; Lovergine, N.; Richter, W.; Tapfer, L. \& Mancini A.M. (2007). GaAs nanowires grown by Au-catalyst assisted MOVPE using tertiarybutyl-arsine as Group-V Precursor. el Cryst. Growth, 298 (January 2007) 620-624, ISSN: 0022-0248.

Pavesi, L. \& Guzzi, M. (1994). Photoluminescence of $\mathrm{Al}_{x} \mathrm{Ga}_{1-x}$ As alloys. I Appl. Phys. 75, 10, (May 1994) 4779-4842, ISSN: 0021-8979 (print), 1089-7550 (online).

Pettersson, H.; Trägårdh, J. Persson A. I., Landin L., Hessman D., and Samuelson, L. (2006). Infrared photodetectors in heterostructure nanowires. Nano Lett. 6 (January 2006) 229-236, ISSN: 0028-0836. 
Piscopiello, E.; Tapfer, L.; Paiano, P.; Prete, P. \& Lovergine, N. (2008). Formation of epitaxial gold nanoislands on (100) silicon. Phys. Rev. B, 78, 3, (July 2008) 035305, 1-7, ISSN 1098-0121 (print), 1550-235X (online).

Prete, P.; Lovergine, N. \& Tapfer, L. (2007). Nanostructure size evolution during Aucatalysed growth by carbo-thermal evaporation of well-aligned $\mathrm{ZnO}$ nanowires on (100)Si. Appl. Phys. A, 88, 1, (April 2007) 21-26, ISSN: ISSN: 0947-8396 (print) ISSN: 1432-0630 (electronic).

Prete, P.; Marzo, F.; Paiano, P.; Lovergine, N.; Salviati, G.; Lazzarini, L. and Sekiguchi, T. (2008). Luminescence of GaAs/AlGaAs core-shell nanowires grown by MOVPE using tertiarybutylarsine. II Cryst. Growth, 310, (January 2008) 5114-5118, ISSN: 0022-0248.

Qi, H.; Gee, P. E. \& Hicks, R. F. (1996). Sites for arsine adsorption on GaAs(001). Surf. Sci. 347, 3, (February 1996) 289-302, ISSN: 0039-6028.

Regolin, I.; Khorenko, V.; Prost, W.; Tegude F.-J.; Sudfeld, D.; Kästner, J. \& Dumpich, G. (2006). Composition control in metal-organic vapor-phase epitaxy grown InGaAs nanowhiskers. el Appl. Phys., 100, 7, (October 2006) 074321, 1-5, ISSN: 0021-8979 (print), 1089-7550 (online).

Samuelson, L.; Thelander, C.; Björk, M.T.; Borgström, M.; Deppert, K.; Dick, K.A.; Hansen, A.E.; Mårtensson, T.; Panev, N.; Persson, A.I.; Seifert, W.; Sköld, N. Larsson, M.W.; Wallenberg, L.R. (2004). Semiconductor nanowires for 0D and 1D physics and applications. Phys. E, 25 (July 2004) 313- 318, ISSN: 1386-9477.

Seifert, W.; Borgström, M.; Deppert, K.; Dick, K.A.; Johansson, J.; Larsson, M.W.; Mårtensson, T.; Sköld, N.; Svensson, C.P.T.; Wacaser, B.A.; Wallenberg, L.R. \& Samuelson, L. (2004). Growth of one-dimensional nanostructures in MOVPE. $d$ Cryst. Growth, 272, (October 2004) 211-220, ISSN: 0022-0248.

Shieh, F.; Saunders, A.E. \& Korgel, B.A. (2005). General shape control of colloidal CdS, CdSe, CdTe quantum rods and quantum rod heterostructures. I Phys. Chem. B, 109, (Dicember 2005) 8538-8542, ISSN (printed): 1089-5647. ISSN (electronic): 1520-5207, and references therein.

Skö1d, N.; Karlsson, L.S.; Larsson, M.W.; Pistol, M.-E.;Seifert, W.; Trägårdh, J. \& Samuelson, L. (2005). Growth and optical properties of strained GaAs-Gax $\operatorname{In}_{1-x} \mathrm{P}$ core-shell nanowires. Nano Lett. 5 (September 2005) 1943-1947, ISSN: 0028-0836.

Spadavecchia, J.; Prete, P.; Lovergine, N.; Tapfer, L. \& Rella, R. (2005). Au nanoparticles prepared by physical method on $\mathrm{Si}$ and sapphire substrates for biosensor applications. el Phys. Chem. B, 109, (August 2005) 17347-17349, ISSN (printed): 10895647. ISSN (electronic): 1520-5207.

Su, W.S.; Chen, T.T.; Cheng, C.L.; Fu, S.P.; Chen, Y.F.; Hsiao, C.L. \& Tu, L.W.(2008). Built-in surface electric field, piezoelectricity and photoelastic effect in $\mathrm{GaN}$ nanorods for nanophotonic devices. Nanotechnol. 19, 11, (June 2008) 235401, 1-5, ISSN: 0957-4484 (print), ISSN 1361-6528 (online).

Svensson, C. P. T.; Seifert, W. ; Larsson, M. W.; Wallenberg, L. R.; Stangl, J.; Bauer, G. \& Samuelson, L. (2005). Epitaxially grown $\mathrm{GaP} / \mathrm{GaAs}_{1-x} \mathrm{P}_{\mathrm{x}} / \mathrm{GaP}$ double heterostructure nanowires for optical applications. Nanotechnol. 16, 6, (April 2005) 936-939, ISSN: 0957-4484 (print), ISSN 1361-6528 (online). 
Thelander, C.; Mårtensson, T.; Bjork, M.T.; Ohlsson, B.J.; Larsson, M.W.; Wallenberg, L.R. \& Samuelson, L. (2003). Single-electron transistors in heterostructure nanowires. Appl. Phys. Lett. 83, (September 2003) 2052-2054, ISSN: 0003-6951.

Thelander, C.; Nilsson, H.A.; Jensen, L.E. \& Samuelson, L. (2005). Nanowire single-electron memory. Nano Lett. 5, (February 2005) 635-638, ISSN: 0028-0836.

Titova, L.V.; Hoang, T.B.; Jackson, H.E.; Smith, L.M.; Yarrison-Rice, J.M.; Kim, Y.; Joyce, H.J.; Tan, H.H.; and Jagadish, C. (2006). Temperature dependence of photoluminescence from single core-shell GaAs-AlGaAs nanowires. Appl. Phys. Lett. 89, (October 2006) 173126, 1-3, ISSN: 0003-6951.

Turkevich, J.; Cooper Stevenson, P. \& Hillier, J. (1951). A study of the nucleation and growth processes in the synthesis of colloidal gold. Discussions Farad. Soc., 11, (December 1951) 55-75, ISSN: 03669033.

Wagner R. S. \& Ellis W.C. (1964). Vapor-Liquid-Solid mechanism of single crystal growth. Appl. Phys. Lett., 4, (March 1964) 89-91, ISSN: 0003-6951.

Walker, C. H.; St. John, J. V. \& Wisian-Neilson P. (2001). Synthesis and size control of gold nanoparticles stabilized by poly(methylphenylphosphazene). I Am. Chem. Soc., 123, 16, (April 2001) 3846- 3847, ISSN: 0002-7863 (print), 1520-5126 (on line).

Wasilewski, Z.R.; Dion, M.M.; Lockwood, D.J.; Poole, P.; Streater, R.W.; Spring Thorpe, A.J. (1997). Composition of AlGaAs. \& Appl. Phys., 81, 4, (February 1997) 1683-1694, ISSN: 0021-8979 (print), 1089-7550 (online).

Wensorra J.; Indlekofer, K.M.; Lepsa, M.I.; Förster, A. \& Lüth, H. (2005). Resonant tunneling in nanocolumns improved by quantum collimation. Nano Lett., 5, (October 2005) 2470-2475, ISSN: 0028-0836.

Wu, Z.H.; Mei, X.Y.; Kim, D.; Blumin, M. \& Ruda, H. (2002). Growth of Au-catalyzed ordered GaAs nanowire arrays by molecular-beam epitaxy. Appl. Phys. Lett., 81, 27, (December 2002) 5177-5179, ISSN: 0003-6951.

Zeng, X.-F.; Chung, D.D.L. \& Lakhani, A. (1987). Effect of heating on the structure of $\mathrm{Au} / \mathrm{GaAs}$ encapsulated with $\mathrm{SiO}_{2}$. Solid St. Electr. 30, 12, (December 1987) 12591266, ISSN: 0038-1101. 


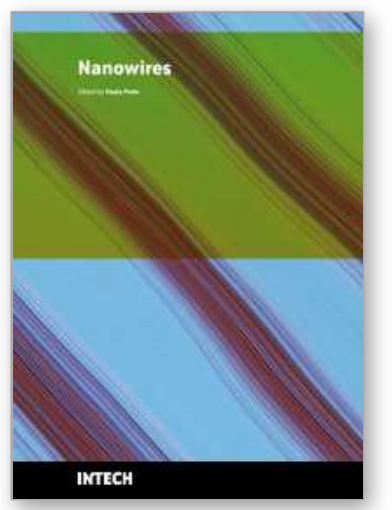

\author{
Nanowires \\ Edited by Paola Prete
}

ISBN 978-953-7619-79-4

Hard cover, 414 pages

Publisher InTech

Published online 01, February, 2010

Published in print edition February, 2010

This volume is intended to orient the reader in the fast developing field of semiconductor nanowires, by providing a series of self-contained monographs focusing on various nanowire-related topics. Each monograph serves as a short review of previous results in the literature and description of methods used in the field, as well as a summary of the authors recent achievements on the subject. Each report provides a brief sketch of the historical background behind, the physical and/or chemical principles underlying a specific nanowire fabrication/characterization technique, or the experimental/theoretical methods used to study a given nanowire property or device. Despite the diverse topics covered, the volume does appear as a unit. The writing is generally clear and precise, and the numerous illustrations provide an easier understanding of the phenomena described. The volume contains 20 Chapters covering altogether many (although not all) semiconductors of technological interest, starting with the IV-IV group compounds ( $\mathrm{SiC}$ and SiGe), carrying on with the binary and ternary compounds of the III-V (GaAs, AIGaAs, GaSb, InAs, GaP, InP, and GaN) and II-VI ( $\mathrm{HgTe}, \mathrm{HgCdTe}$ ) families, the metal oxides ( $\mathrm{CuO}, \mathrm{ZnO}, \mathrm{ZnCoO}$, tungsten oxide, and $\mathrm{PbTiO}$ ), and finishing with $\mathrm{Bi}$ (a semimetal).

\title{
How to reference
}

In order to correctly reference this scholarly work, feel free to copy and paste the following:

Paola Prete and Nicola Lovergine (2010). MOVPE Self-Assembly and Physical Properties of Free-Standing IIIV Nanowires, Nanowires, Paola Prete (Ed.), ISBN: 978-953-7619-79-4, InTech, Available from: http://www.intechopen.com/books/nanowires/movpe-self-assembly-and-physical-properties-of-free-standing-iiiv-nanowires

\section{INTECH}

open science | open minds

\section{InTech Europe}

University Campus STeP Ri

Slavka Krautzeka 83/A

51000 Rijeka, Croatia

Phone: +385 (51) 770447

Fax: +385 (51) 686166

www.intechopen.com
InTech China

Unit 405, Office Block, Hotel Equatorial Shanghai

No.65, Yan An Road (West), Shanghai, 200040, China 中国上海市延安西路65号上海国际贵都大饭店办公楼 405 单元

Phone: +86-21-62489820

Fax: $+86-21-62489821$ 
(C) 2010 The Author(s). Licensee IntechOpen. This chapter is distributed under the terms of the Creative Commons Attribution-NonCommercialShareAlike-3.0 License, which permits use, distribution and reproduction for non-commercial purposes, provided the original is properly cited and derivative works building on this content are distributed under the same license. 